\title{
Proteomic analysis of Citrus sinensis roots and leaves in response to long-term magnesium-deficiency
}

Hao-Yang Peng 1,2,3, Yi-Ping Qi ${ }^{4}$, Jinwook Lee ${ }^{5}$, Lin-Tong Yang ${ }^{1,3}$, Peng Guo ${ }^{1,3}$, Huan-Xin Jiang ${ }^{2,3}$ and Li-Song Chen ${ }^{1,3,6,7^{*}}$

\begin{abstract}
Background: Magnesium (Mg)-deficiency is frequently observed in Citrus plantations and is responsible for the loss of productivity and poor fruit quality. Knowledge on the effects of Mg-deficiency on upstream targets is scarce. Seedlings of 'Xuegan' [Citrus sinensis (L.) Osbeck] were irrigated with Mg-deficient $\left(0 \mathrm{mM} \mathrm{MgSO}_{4}\right)$ or Mg-sufficient $\left(1 \mathrm{mM} \mathrm{MgSO}_{4}\right.$ ) nutrient solution for 16 weeks. Thereafter, we first investigated the proteomic responses of $C$. sinensis roots and leaves to Mg-deficiency using two-dimensional electrophoresis (2-DE) in order to (a) enrich our understanding of the molecular mechanisms of plants to deal with Mg-deficiency and (b) understand the molecular mechanisms by which Mg-deficiency lead to a decrease in photosynthesis.

Results: Fifty-nine upregulated and 31 downregulated protein spots were isolated in Mg-deficient leaves, while only 19 upregulated and 12 downregulated protein spots in Mg-deficient roots. Many Mg-deficiency-responsive proteins were involved in carbohydrate and energy metabolism, followed by protein metabolism, stress responses, nucleic acid metabolism, cell wall and cytoskeleton metabolism, lipid metabolism and cell transport. The larger changes in leaf proteome versus root one in response to Mg-deficiency was further supported by our observation that total soluble protein concentration was decreased by Mg-deficiency in leaves, but unaffected in roots. Mg-deficiency had decreased levels of proteins [i.e. ribulose-1,5-bisphosphate carboxylase (Rubisco), rubisco activase, oxygen evolving enhancer protein 1, photosynthetic electron transfer-like protein, ferredoxin-NADP reductase (FNR), aldolase] involved in photosynthesis, thus decreasing leaf photosynthesis. To cope with Mg-deficiency, C. sinensis leaves and roots might respond adaptively to $\mathrm{Mg}$-deficiency through: improving leaf respiration and lowering root respiration, but increasing (decreasing) the levels of proteins related to ATP synthase in roots (leaves); enhancing the levels of proteins involved in reactive oxygen species (ROS) scavenging and other stress-responsive proteins; accelerating proteolytic cleavage of proteins by proteases, protein transport and amino acid metabolism; and upregulating the levels of proteins involved in cell wall and cytoskeleton metabolism.
\end{abstract}

Conclusions: Our results demonstrated that proteomics were more affected by long-term Mg-deficiency in leaves than in roots, and that the adaptive responses differed between roots and leaves when exposed to long-term Mg-deficiency. Mg-deficiency decreased the levels of many proteins involved in photosynthesis, thus decreasing leaf photosynthesis.

Keywords: Citrus sinensis, Magnesium (Mg)-deficiency, Photosynthesis, Proteomics, Respiration, Reactive oxygen species

\footnotetext{
*Correspondence: lisongchen2002@hotmail.com

${ }^{1}$ College of Resource and Environmental Science, Fujian Agriculture and

Forestry University, Fuzhou 350002, China

${ }^{3}$ Institute of Horticultural Plant Physiology, Biochemistry, and Molecular

Biology, Fujian Agriculture and Forestry University, Fuzhou 350002, China

Full list of author information is available at the end of the article
} 


\section{Background}

Magnesium (Mg), a common constituent in many minerals, comprising $2 \%$ of the Earth's crust, is an essential macronutrient used in large amount by plants for their normal growth and development. Mg-deficiency is a widespread nutritional disorder, affecting productivity and quality in agriculture [1]. $\mathrm{Mg}$ is taken up by plants in the form of divalent $\mathrm{Mg}^{2+}$ (the form of dissolved $\mathrm{Mg}$ in the soil solution). The binding strength of $\mathrm{Mg}^{2+}$ to the soil colloids is low, because $\mathrm{Mg}^{2+}$ has a large hydrated radius. Therefore, $\mathrm{Mg}$ is highly prone to leaching, particularly in acidic soils with low cation exchange capacity. Leaching is considered as a key factor affecting $\mathrm{Mg}$ availability for roots [2]. Mg-deficiency can also be induced by high levels of competing elements, such as potassium $(\mathrm{K})$ and calcium $(\mathrm{Ca})$, which strongly inhibit $\mathrm{Mg}$ uptake by plants [1,3].

Since $\mathrm{Mg}$ is mobile within the plant, $\mathrm{Mg}$-deficiency symptoms first appear on lower and older leaves. The typical symptom of Mg-deficiency is leaf interveinal chlorosis [4]. Although Mg-deficiency symptoms are well described in plant shoots, the responses of both plant root growth and biomass allocation between roots and shoots to $\mathrm{Mg}$ deficiency is more variable. Previous study showed a less severe impact on root growth or shoot growth, depending on the plant species and the system used to create Mg-deficiency [1]. $\mathrm{Mg}$ is the central component of the chlorophyll (Chl) molecule and plays a crucial role in photosynthesis such as Chl biosynthesis, photochemical reactions, $\mathrm{CO}_{2}$ fixation and stomata functioning $[1,5]$. $\mathrm{Mg}$-deficiency-induced inhibition of photosynthesis is a wide phenomenon observed in many plant species [4-6]. In addition, $\mathrm{Mg}$ also act as a cofactor and allosteric modulator for more than 300 enzymes including ribulose-1, 5-bisphosphate carboxylase (Rubisco), ATPase, protein kinases, RNA polymerase, phosphatases and glutathione synthase $[1,4]$. Therefore, $\mathrm{Mg}$ also functions in many other physiological processes, such as respiration [7], glycolysis, tricarboxylic acid (TCA) cycle [8], energy transfer via adenosine triphosphate [9], carbohydrate partitioning between source and sink organs $[1,10]$, reactive oxygen species (ROS) formation and related photooxidative damage $[5,11]$, protein biosynthesis, and the formation of DNA and RNA [3]. Accordingly, a number of studies have investigated the effects of Mg-deficiency on Chl synthesis, transport and utilization of photosynthates [1], photochemical reactions, $\mathrm{CO}_{2}$ fixation [2,4-6], respiration, TCA cycle $[7,8]$, and ROS metabolism $[4,5,11]$.

Physiological and molecular biological analyses have allowed us to draw a picture of abiotic stress responses in various plants. Although the physiological targets upon Mg-deficiency have been reported by many workers in various plants $[1,4]$, the knowledge of upstream molecular targets is very limited until recently. Hermans et al. [12,13] investigated the transcriptomic responses to 4,8 and $24 \mathrm{~h}$ Mg-deficiency, or long-term (1 week) Mg-deficiency and restoration in Arabidopsis thaliana roots and leaves and identified numerous target genes involved in the circadian clock, the redox control of the cell and the protection of the photosynthetic apparatus. It is worth mentioning that the responses of global transcriptomics to Mg-deficiency were asynchronized, with a higher number of differentially expressed genes after 4 or $8 \mathrm{~h}$ in roots and after $28 \mathrm{~h}$ or 1 week in leaves. While these data are very useful, the abundances of mRNAs does not necessarily correspond directly the abundances of their corresponding proteins. The level of a protein depends not only on transcription rates of the gene, but also on nuclear export and mRNA localization, transcript stability, translational regulation and protein degradation. Indeed, there is considerable variability on protein level versus mRNA level [14]. Since biological processes are ultimately controlled by proteins, a proteomic analysis is necessary to get a better understanding of the plant responses to $\mathrm{Mg}$-deficiency. To our knowledge, little information is available on the changes of protein profile under $\mathrm{Mg}$-deficiency in plant roots and leaves [1].

In China, Mg-deficiency is frequently observed in Citrus plantations and is responsible for the loss of productivity and poor fruit quality [5]. Although the effects of $\mathrm{Mg}$-deficiency on Citrus $\mathrm{CO}_{2}$ assimilation, photosynthetic electron transport and antioxidant system, carbohydrates and organic acid metabolism have been investigated by a few researchers $[5,6,8]$, the knowledge of upstream targets is scarce. In the present study, we first investigated the proteomic responses of Citrus leaves and roots to $\mathrm{Mg}$ deficiency using two-dimensional electrophoresis (2-DE) in order to (a) enrich our understanding of the molecular mechanisms of plants to deal with Mg-deficiency and (b) understand the molecular mechanisms by which $\mathrm{Mg}$ deficiency lead to a decrease in $\mathrm{CO}_{2}$ assimilation.

\section{Results}

Seedling growth, leaf, stem and root Mg concentration

Plant treated with $0 \mathrm{mM} \mathrm{Mg}$ displayed decreased leaf, stem and root dry weight (DW) and lower concentration of $\mathrm{Mg}$ in leaves, stems and roots (Figure 1), and leaf $\mathrm{Mg}$ concentration was much lower than the normal range [15]. Based on these results, plants that did not receive $\mathrm{Mg}$ are considered Mg-deficient, and those treated with $1 \mathrm{mM} \mathrm{Mg}$ are considered Mg-sufficient (control).

\section{Leaf gas exchange, leaf and root respiration and total soluble protein concentration}

Compared with controls, Mg-deficient leaves had lower $\mathrm{CO}_{2}$ assimilation (Figure 2A), stomatal conductance (Figure 2B) and transpiration (Figure 2D), and higher intercellular $\mathrm{CO}_{2}$ concentration (Figure 2C). 


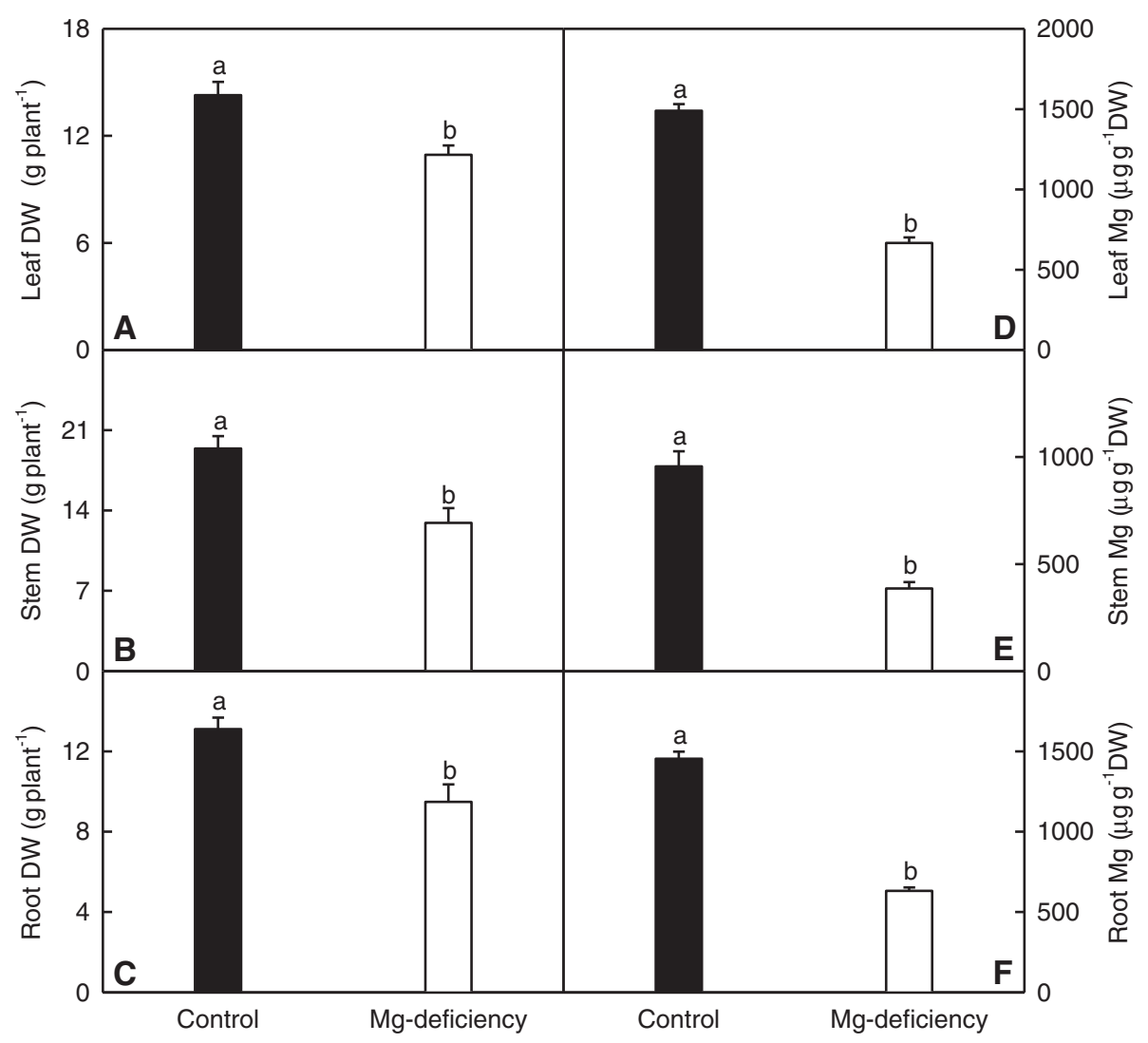

Figure 1 Effects of Mg-deficiency on growth and Mg concentration in leaves, stems and roots. (A-C) Leaf, stem and root DW. (D-F) Leaf, stem and root Mg concentration. Bars represent means \pm SE ( $n=10$ except for 9 for leaf, stem and root DW of Mg-deficient seedlings). Different letters above the bars indicate a significant difference at $P<0.05$.

Mg-deficient leaves displayed increased dark respiration (Figure 2E) and decreased concentration of total soluble proteins (Figure 2F), while Mg-deficient roots had decreased respiration (Figure 2G) and unchanged concentration of total soluble proteins (Figure 2H).

\section{Profiles of differentially expressed proteins}

2-DE was performed to compare the protein profiles between control and $\mathrm{Mg}$-deficient roots and leaves. In order to get credible results, the experiments were performed in 3 biological replicates. After Coomassie Brilliant Blue G-250 staining, more than 900 clear and reproducible spots were detected on each gel (Figures 3 and 4). Comparative analysis of the 2-DE maps of control and Mg-deficient leaves was performed by PDQuest 8.0.1 software. A protein spot was considered differentially expressed when the protein had both a fold change of more than 2 and a $P$-value less than 0.05 . Based on the two criteria, 90 (ca.10.0\% of the total protein spots) differentially expressed protein spots were detected in Mg-deficient leaves with high confidence, 59 of which displayed increased and 31 displayed decreased level under Mg-deficient condition; and 32 (ca. 3.6\% of the total protein spots) differentially expressed protein spots were detected in Mg-deficient roots with high confidence, including 20 protein spots that were upregulated and 12 protein spots that were downregulated by $\mathrm{Mg}$ deficiency.

All these differentially expressed protein spots were excised from the 2-DE gels and submitted to MALDITOF/TOF-MS and LTQ-ESI-MS/MS. In total, 90 and 31 protein spots were identified in $\mathrm{Mg}$-deficient leaves and roots, respectively. The database searching results are presented in Tables 1 and 2. According to the biological functional properties, these differentially expressed protein spots in Mg-deficient leaves were classified into the following functional categories: carbohydrate and energy metabolism (36.7\%), protein metabolism (22.2\%), stress responses (15.6\%), nucleic acid metabolism (4.4\%), cell wall and cytoskeleton metabolism (3.3\%), cell transport (2.2\%), lipid metabolism (2.2\%), other and unknown biological processes (13.3\%) (Table 1 and Figure 5); and theses protein spots in $\mathrm{Mg}$-deficient roots were involved in carbohydrate and energy metabolism (29.0\%), protein metabolism (25.8\%), stress responses (12.9\%), nucleic acid metabolism (9.7\%), cell wall and cytoskeleton metabolism 


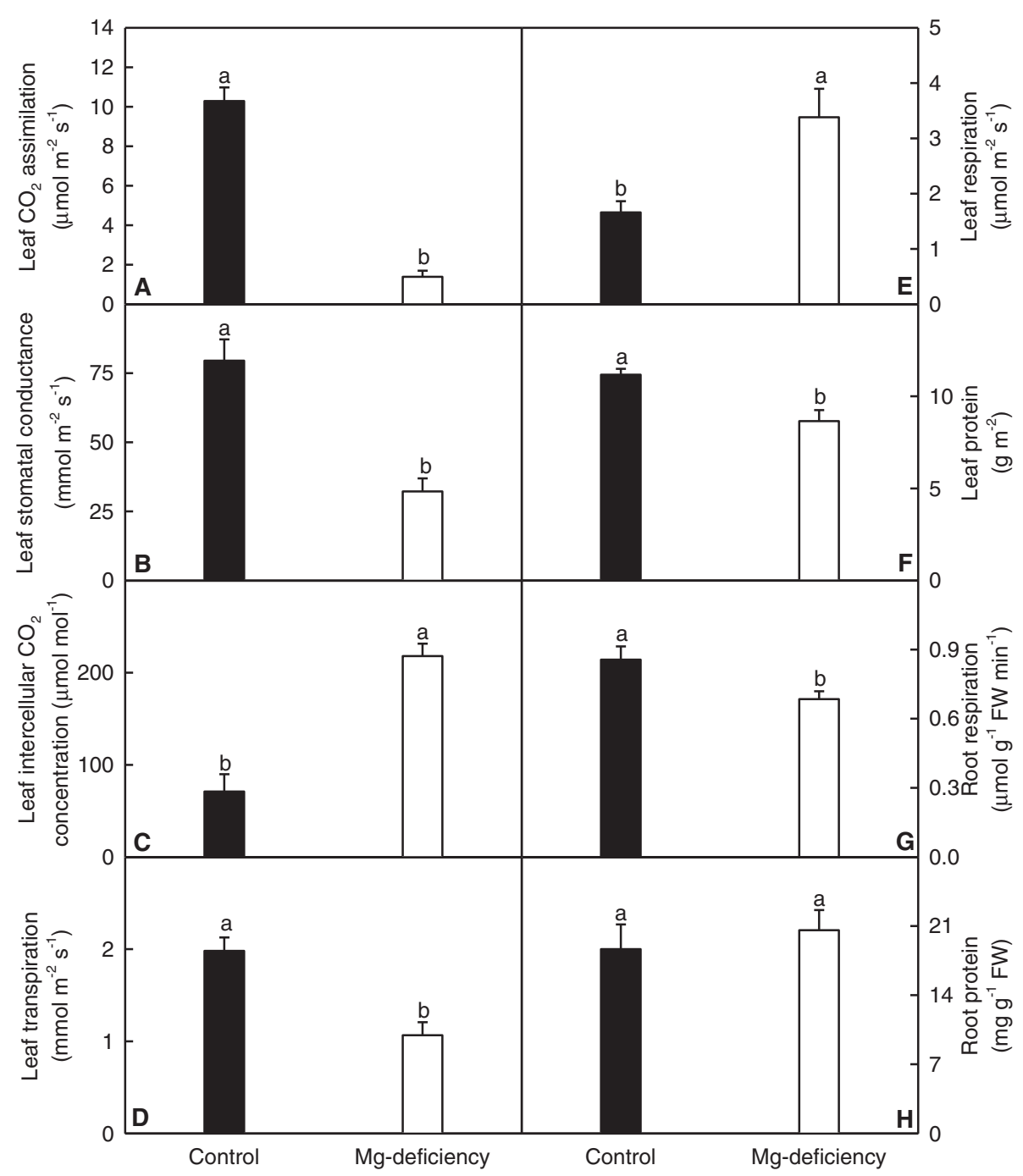

Figure 2 Effects of Mg-deficiency on leaf gas exchange, root respiration, and root and leaf total soluble protein. (A-E) Leaf $\mathrm{CO}_{2}$ assimilation, stomatal conductance, intercellular $\mathrm{CO}_{2}$ concentration, transpiration and respiration. (F) Leaf total soluble protein. (G) Root respiration. (H) Root total soluble protein. Bars represent means $\pm \mathrm{SE}\left(n=5\right.$ except for 8 for leaf $\mathrm{CO}_{2}$ assimilation, stomatal conductance, intercellular $\mathrm{CO}_{2}$ concentration and transpiration of control and $\mathrm{Mg}$-deficient seedlings, respectively). Different letters above the bars indicate a significant difference at $P<0.05$.

(9.7\%), lipid metabolism (6.5\%), other and unknown biological processes (6.5\%) (Table 2 and Figure 5).

\section{Principal component analysis (PCA) loading plots and correlation}

The majority of differentially expressed proteins involved in protein metabolism and stress responses were highly clustered under Mg-deficient leaves. Furthermore, the differentially expressed proteins associated with nucleic acid metabolism, cell transport, lipid metabolism, and cell wall and cytoskeleton metabolism were only plotted in Mg-deficient leaves (Figure 6A). However, the differentially expressed proteins in nucleic acid metabolism were clustered in control roots. The proteins in cell wall and cytoskeleton metabolism were only plotted in $\mathrm{Mg}$ deficient roots (Figure 6B).

The correlation coefficient matrix presented that the individual differentially expressed proteins were highly correlated within each categorized metabolism, regardless of tissues (Figure 7). In leaves, the majority of the differentially expressed proteins in carbohydrate and energy metabolism were positively correlated with each other but negatively with the other proteins in the other metabolisms. The most proteins in the other metabolisms but carbohydrate and energy metabolism were highly positively correlated with each other (Figure 7A). In contrast, the differentially expressed proteins in roots did not show any clear pattern like those in leaves (Figure 7B). 

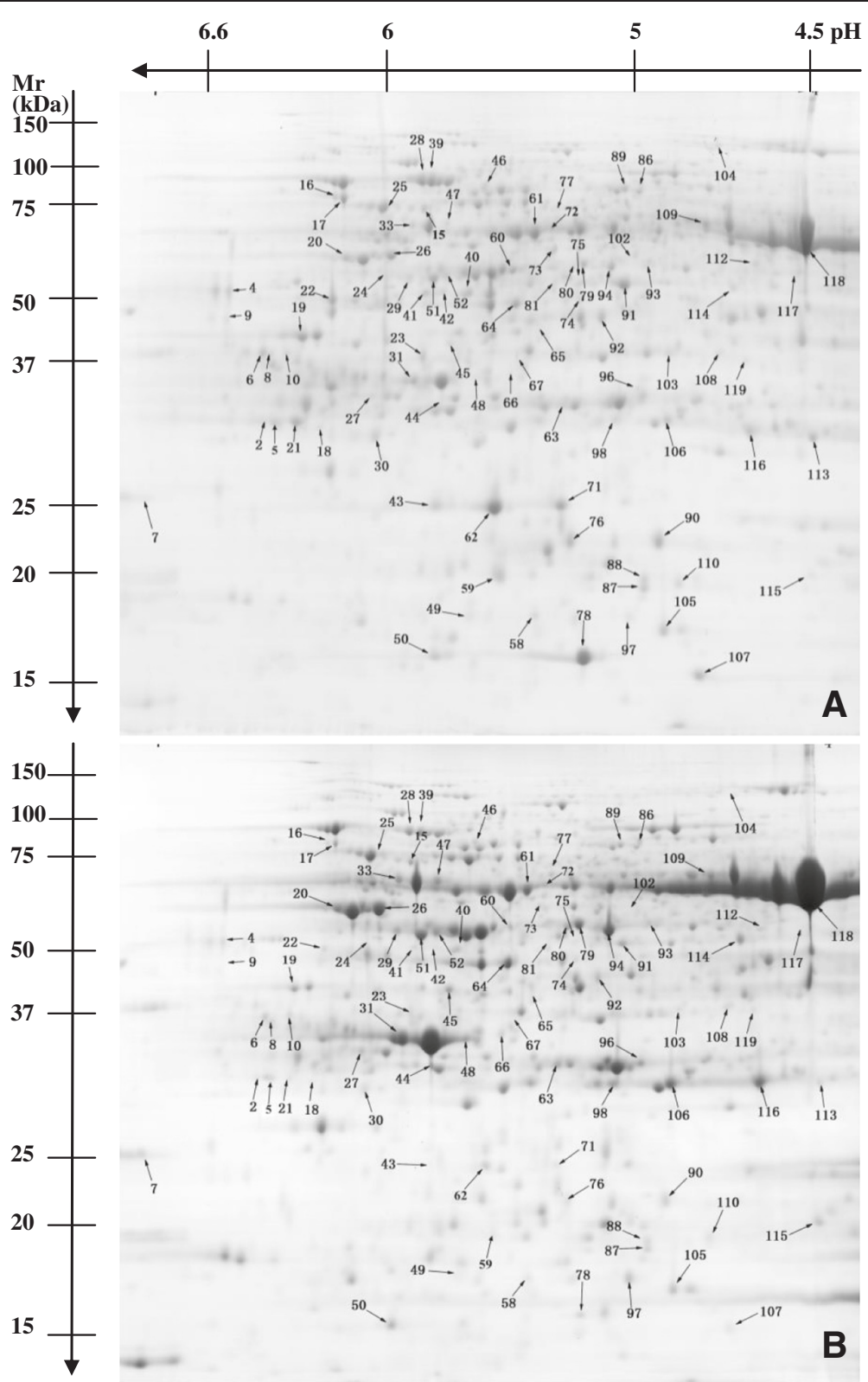

Figure 3 Representative gel images of proteins in Mg-deficient (A) and control (B) leaves. Proteins were separated in the first dimension on an IPG strip pH 3-7 and in the second dimension on a 12\% slab gel, followed by colloidal Coomassie Brilliant G-250. An equal amount (1.5 mg) of total protein extracts was loaded in each gel.

\section{Transcriptional analysis of genes for some differentially expressed proteins}

To verify the changed expression in transcriptional level and evaluate the correlation between mRNA and protein levels. The expression levels of genes for 18 differentially expressed proteins from $\mathrm{Mg}$-deficient leaves (i.e. $\mathrm{L} 4,33$, 44, 78, 80, 96, 102, 104, 105, 110, 114, 117 and 118) and roots (i.e. R1, 13, 85, 95 and 121) were analyzed by qRTPCR (Figure 8). Of the 18 genes, the expression profiles of nine genes (i.e. L4, 33, 44, 80, 96, 104 and 114, and R13 and 121) were well correlated with our 2-DE data
(Tables 1 and 2), meaning that the differentially expressed proteins are regulated at the transcriptional level. However, the transcript level changes of the remaining nine genes (i.e. L78, 102, 105, 100, 117 and 118, and R1, 85 and 95) did not match the proteomic observations (Tables 1 and 2). Indeed, the transcript levels of genes do not necessarily match the levels of their corresponding proteins, since the abundance of a protein depends not only on transcription rate of the gene expression alone $[14,16]$. The discrepancy between the expression levels of the nine genes and the abundance of the corresponding protein 

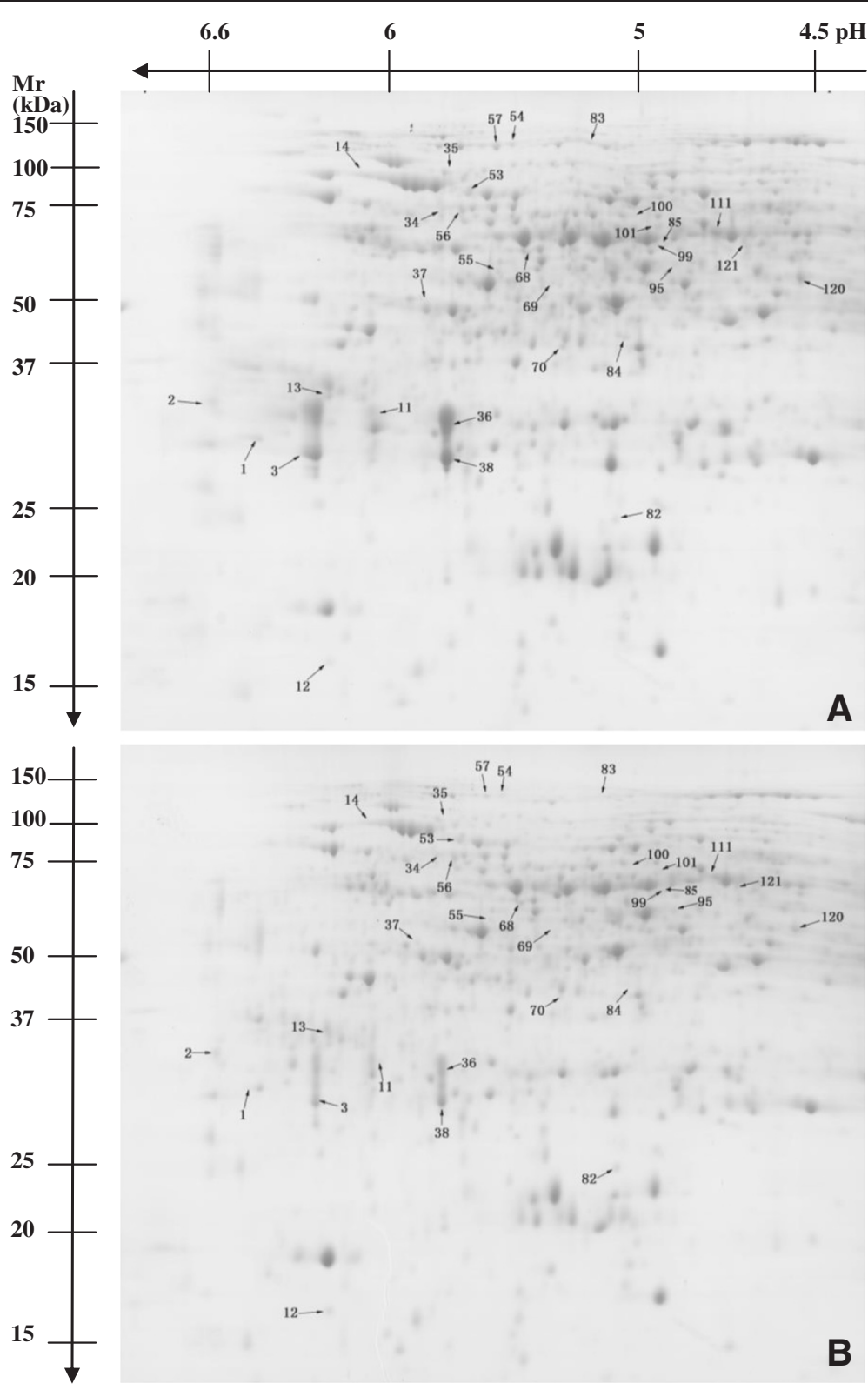

Figure 4 Representative gel images of proteins in Mg-deficient (A) and control (B) roots. Proteins were separated in the first dimension on an IPG strip pH 3-7 and in the second dimension on a 12\% slab gel, followed by colloidal Coomassie Brilliant G-250. An equal amount (1.5 mg) of total protein extracts was loaded in each gel.

(Table 2 and Figure 8) suggests that post-translational modifications (PTMs) might influence the abundances of these proteins and alter the positions of these proteins on the gel.

\section{Discussion}

\section{Mg-deficiency triggers different responses in leaves and} roots

Our results showed that the amounts of differentially expressed proteins were much more in the $\mathrm{Mg}$-deficient leaves than in the Mg-deficient roots (Tables 1 and 2;
Additional file 1), meaning that the effects of long-term Mg-deficiency on protein profiles of leaves were more pronounced than on those of roots. This agrees with the reports in A. thaliana that the root transcriptome was less severely affected by long-term (1 week) Mg-deficiency [13], and that the responses of plants to $\mathrm{Mg}$-deficiency was asynchronized, with a lower number of differentially regulated genes in leaves 4 or $8 \mathrm{~h}$ after the removal of $\mathrm{Mg}$ from the nutrient solution and in roots $28 \mathrm{~h}$ after the removal of $\mathrm{Mg}$ [12]. This is also supported by our results that $\mathrm{Mg}$-deficiency decreased leaf concentration of total 
Table 1 List of differentially expressed proteins identified using MALDI-TOF/TOF-MS in magnesium (Mg)-deficient Citrus sinensis leaves

\begin{tabular}{|c|c|c|c|c|c|c|c|}
\hline Spot no. ${ }^{a}$ & Accession no. ${ }^{b}$ & Protein identity & Organism & MW (kDa) & $\mathrm{MP} / \mathrm{SC}$ & Score & Ratio $^{c}$ \\
\hline \multicolumn{8}{|c|}{ Carbohydrate and energy metabolism } \\
\hline L118 & gi|4206520 & Ribulose 1,5-bisphosphate carboxylase, partial & Severinia buxifolia & 49.67 & $23 / 86$ & 450 & 0.267 \\
\hline L20 & gi|19992 & Ribulose bisphosphate carboxylase activase & Nicotiana tabacum & 25.91 & $14 / 92$ & 418 & 0.478 \\
\hline L24 & gi|290766483 & Rubisco activase & Glycine max & 52.39 & 19/90 & 315 & 0.051 \\
\hline L26 & gi|19992 & Ribulose bisphosphate carboxylase activase & N. tabacum & 25.91 & $14 / 95$ & 398 & 0.259 \\
\hline L31 & gi|19992 & Ribulose bisphosphate carboxylase activase & N. tabacum & 25.91 & $15 / 94$ & 435 & 0.170 \\
\hline L51 & gi|100380 & Ribulose-bisphosphate carboxylase activase & & 25.91 & $13 / 96$ & 397 & 0.388 \\
\hline L52 & gi|19992 & Ribulose-bisphosphate carboxylase activase & N. tabacum & 25.91 & $11 / 98$ & 264 & 0.190 \\
\hline L48 & gi|326467059 & Oxygen evolving enhancer protein 1 & Litchi chinensis & 35.17 & $14 / 96$ & 288 & 0.020 \\
\hline L115 & gi|89475526 & Photosynthetic electron transfer-like protein & Panax ginseng & 19.64 & $5 / 103$ & 93 & 0.412 \\
\hline L119 & gi|158145455 & Putative ferredoxin-NADP reductase & Solanum peruvianum & 18.02 & $11 / 98$ & 111 & 0.325 \\
\hline L114 & gi|77540212 & $\begin{array}{l}\text { Glyceraldehyde-3-phosphate dehydrogenase B } \\
\text { subunit }\end{array}$ & Glycine max & 48.20 & $13 / 96$ & 167 & 0.323 \\
\hline L80 & gi|313585890 & Phosphoglycerate kinase & Nicotiana benthamiana & 50.05 & $14 / 93$ & 357 & 0.239 \\
\hline L93 & gi|313585890 & Phosphoglycerate kinase & N. benthamiana & 50.05 & $11 / 99$ & 281 & 0.346 \\
\hline L94 & gi|1161600 & Phosphoglycerate kinase & N. tabacum & 50.15 & $20 / 90$ & 565 & 0.457 \\
\hline L106 & gi|255567325 & Carbonic anhydrase, putative & Ricinus communis & 35.64 & $4 / 106$ & 83 & 0.295 \\
\hline$\llcorner 44$ & gi|295687231 & Triosephosphate isomerase & Gossypium hirsutum & 33.10 & $7 / 102$ & 121 & 0 \\
\hline L108 & gi|330252068 & Fructose-bisphosphate aldolase, class I & Arabidopsis thaliana & 41.78 & $10 / 98$ & 138 & 0.442 \\
\hline L67 & gi|332196500 & Putative lactoylglutathione lyase, chloroplast & A. thaliana & 39.14 & $17 / 82$ & 58 & 0 \\
\hline L81 & gi|642352 & Malate dehydrogenase (NADP) & Spinacia oleracea & 47.46 & $1 / 98$ & 23 & 2.320 \\
\hline L89 & gi|255579273 & Succinate dehydrogenase, putative & R. communis & 68.46 & $23 / 87$ & 293 & 2.438 \\
\hline L104 & gi|285309967 & Aconitate hydratase 3 & Citrus clementina & 98.04 & $30 / 78$ & 330 & 3.176 \\
\hline L112 & gi|255578100 & $\begin{array}{l}\text { Dihydrolipoamide succinyltransferase component } \\
\text { of 2-oxoglutarate dehydrogenase, putative }\end{array}$ & R. communis & 50.84 & $9 / 99$ & 115 & 2.262 \\
\hline L72 & gi|289600010 & 2-Phospho-D-glycerate hydrolase & Citrus trifoliata & 47.76 & $5 / 98$ & 449 & 3.389 \\
\hline L86 & gi|332190370 & $\begin{array}{l}\text { 2,3-Bisphosphoglycerate-independent } \\
\text { phosphoglycerate mutase } 1\end{array}$ & A. thaliana & 60.54 & $20 / 90$ & 314 & 3.775 \\
\hline L60 & gi|20336385 & Alpha-amylase & Citrus reticulata & 17.05 & $9 / 101$ & 220 & 4.083 \\
\hline L77 & gi|7671230 & ADP-glucose pyrophosphorylase catalytic subunit & Perilla frutescens & 57.44 & $16 / 83$ & 63 & 2.080 \\
\hline L61 & gi|56784991 & Putative ATP synthase beta subunit & Oryza sativa Japonica Group & 45.88 & $22 / 88$ & 706 & 0.280 \\
\hline L65 & gi|332191230 & ATP synthase gamma chain 2 & A. thaliana & 42.65 & $7 / 102$ & 88 & 0.101 \\
\hline L33 & gi|113952607 & ATP synthase CF1 alpha subunit, chloroplastic & C. sinensis & 55.45 & $32 / 78$ & 781 & 0.205 \\
\hline L47 & gi|122166198 & ATP synthase subunit alpha,chloroplastic & & 55.45 & $30 / 80$ & 632 & 0.218 \\
\hline L40 & gi|41350585 & Putative adenosine kinase & $\begin{array}{l}\text { Populus tremula } \times \text { Populus } \\
\text { alba }\end{array}$ & 24.99 & $6 / 104$ & 82 & 2.174 \\
\hline L105 & gi|255571035 & Nucleoside diphosphate kinase, putative & R. communis & 16.30 & $3 / 104$ & 116 & 3.070 \\
\hline L117 & gi|33149683 & Alcohol dehydrogenase & Dianthus caryophyllus & 41.23 & $8 / 101$ & 284 & 100 \\
\hline \multicolumn{8}{|c|}{ Protein metabolism } \\
\hline L79 & gi|255540493 & Elongation factor tu, putative & Ricinus communis & 50.09 & $20 / 90$ & 505 & 0.357 \\
\hline L25 & gi|806808 & Chaperonin precursor (chloroplast) & Pisum sativum & 62.95 & $13 / 97$ & 177 & 100 \\
\hline L71 & gi|3098188 & Small ribosomal protein 4, partial (chloroplast) & Plagiomnium affine & 22.29 & $12 / 97$ & 57 & 24.429 \\
\hline L88 & gi|193788982 & Ribosomal protein S3 & Trifolium subterraneum & 24.57 & $9 / 100$ & 51 & 2.067 \\
\hline L109 & gi|12802327 & Mitochondrial processing peptidase beta subunit & Cucumis melo & 58.85 & $17 / 91$ & 269 & 100 \\
\hline L41 & gi|332005228 & F-box domain-containing protein & A. thaliana & 50.19 & $15 / 94$ & 57 & 3.351 \\
\hline
\end{tabular}


Table 1 List of differentially expressed proteins identified using MALDI-TOF/TOF-MS in magnesium (Mg)-deficient Citrus sinensis leaves (Continued)

\begin{tabular}{|c|c|c|c|c|c|c|c|}
\hline L8 & gi|31433129 & F-box family protein, putative, expressed & O. sativa Japonica Group & 34.58 & $11 / 98$ & 57 & 100 \\
\hline L9 & gi|334302804 & Putative F-box/kelch-repeat protein & & 42.48 & $16 / 94$ & 67 & 100 \\
\hline L62 & gi|12324823 & Putative RING zinc finger protein & A. thaliana & 12.29 & $11 / 99$ & 61 & 21.438 \\
\hline$\llcorner 4$ & gi|89274062 & Cysteine proteinase & Platycodon grandiflorus & 50.77 & $6 / 101$ & 91 & 3.780 \\
\hline L6 & gi|89274062 & Cysteine proteinase & P. grandiflorus & 50.77 & $10 / 96$ & 63 & 17.176 \\
\hline L45 & gi|255538698 & Proteasome subunit alpha type, putative & R. communis & 30.35 & $11 / 98$ & 249 & 3.490 \\
\hline$\llcorner 49$ & gi|332656653 & Putative cathepsin B-like cysteine protease & A. thaliana & 39.32 & $8 / 100$ & 148 & 100 \\
\hline L58 & gi|332656653 & Putative cathepsin B-like cysteine protease & A. thaliana & 39.32 & $9 / 98$ & 156 & 7.633 \\
\hline L27 & gi|9280680 & F2E2.12 & A. thaliana & 12.88 & 9/99 & 55 & 0.476 \\
\hline L98 & gi|193848487 & Putative skp1 protein & Brachypodium distachyon & 18.69 & $10 / 100$ & 57 & 0.442 \\
\hline L75 & gi|121489623 & Putative glutamine synthetase & P. sativum & 39.02 & $10 / 99$ & 136 & 7.333 \\
\hline L91 & gi|121489623 & Putative glutamine synthetase & P. sativum & 39.02 & $10 / 100$ & 196 & 2.087 \\
\hline L102 & gi|297843044 & S-adenosylmethionine synthetase & $\begin{array}{l}\text { Arabidopsis lyrata subsp. } \\
\text { lyrata }\end{array}$ & 41.43 & $18 / 91$ & 230 & 100 \\
\hline L113 & gi|18150415 & Glutathione S-transferase & Allium cepa & 23.43 & $1 / 96$ & 55 & 2.873 \\
\hline \multicolumn{8}{|c|}{ Stress responses } \\
\hline L50 & gi|2274917 & Cu/Zn superoxide dismutase & Citrus sinensis & 12.78 & $8 / 102$ & 259 & 100 \\
\hline L78 & gi|2274917 & $\mathrm{Cu} / \mathrm{Zn}$ superoxide dismutase & C. sinensis & 12.78 & $6 / 102$ & 127 & 22.111 \\
\hline L63 & gi|221327589 & Ascorbate peroxidase 2 & Citrus maxima & 27.56 & $18 / 91$ & 230 & 3.426 \\
\hline L96 & gi|189476292 & Ascorbate peroxidase & C. maxima & 22.65 & $10 / 97$ & 313 & 100 \\
\hline L97 & gi|186920323 & Chloroplast Cu/Zn superoxide dismutase & Hevea brasiliensis & 6.92 & $6 / 80$ & 219 & 0.410 \\
\hline L74 & gi|223543700 & Aldo/keto reductase, putative & R. communis & 37.98 & $8 / 99$ & 103 & 3.418 \\
\hline L103 & gi|255543887 & Aldo-keto reductase, putative & R. communis & 34.84 & $5 / 104$ & 102 & 7.957 \\
\hline L28 & gi|20559 & Heat shock protein 70 & Petunia $\times$ hybrida & 70.74 & $33 / 77$ & 523 & 2.595 \\
\hline L39 & gi|211906496 & Heat shock protein 70 & Gossypium hirsutum & 71.17 & $34 / 76$ & 456 & 3.219 \\
\hline$\llcorner 46$ & gi|300265 & HSP68 = 68 kda heat-stress DnaK homolog & Lycopersicon peruvianum & 62.34 & $15 / 94$ & 79 & 3.960 \\
\hline L59 & gi|259123935 & Cll small heat shock protein 1 & Prunus salicina & 17.52 & $6 / 10$ & 102 & 314.482 \\
\hline L76 & gi|116643152 & Stress-related protein & Citrus sinensis & 17.59 & $14 / 94$ & 310 & 6.476 \\
\hline L90 & gi|116643152 & Stress-related protein & Citrus sinensis & 17.59 & $14 / 95$ & 382 & 4.825 \\
\hline L116 & gi|332661276 & Late embryogenesis abundant (LEA) protein & A. thaliana & 37.94 & $12 / 98$ & 47 & 0.441 \\
\hline \multicolumn{8}{|c|}{ Nucleic acid metabolism } \\
\hline L5 & gi|89258208 & Maturase, partial (mitochondrion) & Nepenthes sp. 'Kosobe' & 67.36 & $16 / 94$ & 54 & 3.741 \\
\hline L17 & gi|115466830 & Os06g0187000 protein & Oryza sativa Japonica Group & 91.71 & $17 / 92$ & 56 & 3.776 \\
\hline L22 & gi|4063759 & Mutator-like transposase & A. thaliana & 80.331 & $18 / 92$ & 65 & 14.059 \\
\hline L73 & gi|255560725 & Dead box ATP-dependent RNA helicase & R. communis & 46.812 & $27 / 81$ & 393 & 2.228 \\
\hline \multicolumn{8}{|c|}{ Cell wall and cytoskeleton metabolism } \\
\hline L16 & gi|56603655 & Myosin class 11-1 & Adiantum capillus-veneris & 173.69 & $27 / 82$ & 63 & 2.339 \\
\hline L21 & gi|216296850 & UGT1 (UDP-glucosyltransferase) & $\begin{array}{l}\text { Pueraria montana var. } \\
\text { lobata }\end{array}$ & 52.19 & $13 / 97$ & 56 & 23.600 \\
\hline L107 & gi|38260664 & Pollen coat oleosin-glycine rich protein & Olimarabidopsis pumila & 47.00 & $12 / 98$ & 39 & 100 \\
\hline \multicolumn{8}{|c|}{ Cell transport } \\
\hline L87 & gi|108707728 & $\begin{array}{l}\text { Mitochondrial import inner membrane translocase } \\
\text { subunit Tim17/Tim22/Tim23 family protein, putative }\end{array}$ & Oryza sativa Japonica Group & 18.36 & $1 / 96$ & 34 & 4.384 \\
\hline
\end{tabular}


Table 1 List of differentially expressed proteins identified using MALDI-TOF/TOF-MS in magnesium (Mg)-deficient Citrus sinensis leaves (Continued)

\begin{tabular}{|c|c|c|c|c|c|c|c|}
\hline L110 & gi|297793335 & ATYKT62 & A. lyrata subsp. lyrata & 22.64 & $7 / 52$ & 51 & 100 \\
\hline \multicolumn{8}{|c|}{ Lipid metabolism } \\
\hline$\llcorner 43$ & gi|108707070 & $\begin{array}{l}\text { Type I inositol-1,4,5-trisphosphate 5-phosphatase } \\
\text { CVP2, putative }\end{array}$ & Oryza sativa Japonica & 54.41 & $14 / 94$ & 56 & 100 \\
\hline L19 & gi|255545978 & Cytochrome P450, putative & R. communis & 77.12 & $15 / 95$ & 48 & 2.320 \\
\hline \multicolumn{8}{|c|}{ Other and unknown biological processes } \\
\hline L10 & gi|163943829 & Ent-kaurene synthase & Luziola fluitans & 42.96 & $13 / 96$ & 53 & 100 \\
\hline L66 & gi|255547472 & 4-Nitrophenylphosphatase, putative & R. communis & 39.69 & $17 / 92$ & 167 & 0 \\
\hline L29 & gi|825532 & Orf & Pseudotsuga menziesii & 17.00 & $8 / 99$ & 51 & 0.350 \\
\hline L23 & gi|2582665 & Thi & C. sinensis & 37.57 & $21 / 89$ & 197 & 8.333 \\
\hline L15 & gi|108711987 & $\begin{array}{l}\text { Streptomyces cyclase/dehydrase family protein, } \\
\text { expressed }\end{array}$ & Oryza sativa Japonica Group & 57.34 & $15 / 76$ & 60 & 2.595 \\
\hline L30 & gi|147855631 & Hypothetical protein VITISV_019248 & Vitis viniferai & 35.05 & $12 / 98$ & 346 & 2.365 \\
\hline L64 & gi|302810346 & Hypothetical protein SELMODRAFT_182694 & Selaginella moellendorffii & 47.01 & 9/101 & 215 & 0.480 \\
\hline L42 & gi|147812626 & Hypothetical protein VITISV_007608 & Vitis vinifera & 27.14 & $8 / 101$ & 167 & 11.185 \\
\hline L18 & gi|326530266 & Predicted protein & $\begin{array}{l}\text { Hordeum vulgare subsp. } \\
\text { vulgare }\end{array}$ & 62.53 & $17 / 92$ & 59 & 6.750 \\
\hline L32 & gi|296086060 & Unamed protein product & V. vinifera & 17.29 & $18 / 91$ & 234 & 100 \\
\hline L7 & gi|296089720 & Unnamed protein product & V. vinifera & 27.96 & $7 / 85$ & 55 & 0.160 \\
\hline L92 & gi|147821099 & Hypothetical protein VITISV_038267 & V. vinifera & 39.24 & $11 / 99$ & 66 & 3.538 \\
\hline
\end{tabular}

MP/SC: Number of matched peptides/sequence coverage percentage; MW: Theoretical molecular weigh;

a: Spot number corresponds to the 2-DE gel in Figure 3.

${ }^{b}$ : gi number is from NCBI database of matched protein.

c: Ratio means the ratio of $\mathrm{Mg}$-deficiency to control; 0 means protein spots were only detected in control roots; 100 means protein spots were only detected in the Mg-deficient roots.

soluble proteins (Figure 2F), but had no influence on root concentration of total soluble proteins (Figure $2 \mathrm{H}$ ). As shown in Tables 1 and 2, the majority of the differentially expressed proteins only presented in roots or leaves, only two differentially expressed proteins with the same gi number presented in both roots and leaves [i.e. alcohol dehydrogenase (ADH, gi|33149683), which increased in leaves (L117) and roots (R120) in response to $\mathrm{Mg}$ deficiency; and chaperonin precursor (gi|806808), which increased in Mg-deficient leaves (L25) and decreased in Mgdeficient roots (R34 and 56)]. In leaves, the abundances of putative ferredoxin-NADP reductase (FNR, L119) and ATP synthase (L33, 47 and 65) decreased and the levels of proteins involved in TCA cycle (L81, L89 and L104) as well as dark respiration were increased in response to Mg-deficiency; whereas in roots, the levels of FNR (R38) and ATPase $\alpha$ subunit, partial (mitochondrion, R111) were upregulated and the abundance of pyruvate decarboxylase, putative (R85) as well as respiration was downregulated by Mg-deficiency. In conclusion, there are many differences in Mg-deficiency-induced changes in protein profiles as well as biochemical responses between leaves and roots.
As shown in Tables 1 and 2, Mg-deficiency did not alter the abundances of these proteins potentially involved in mediating $\mathrm{Mg}$ transport such as the MAGNESIUMPROTON EXCHANGER 1 (MHX1) and the MITOCHONDRIAL RNA SPLICING 2 MAGNESIUM TRANSPORTER (MRS2 MGT/CorA) family [17]. This agrees with the reports that $\mathrm{Mg}$-deficiency did not induce the expression of genes associated with the transport of $\mathrm{Mg}$, with the only exception of the MRS2-9 being downregulated $[12,13]$.

Some differentially expressed proteins [i.e. Rubisco activase (L20, 24, 26, 31 and 51), phosphoglycerate kinase (L80, 93 and 94), cysteine proteinase (L4 and 6)] in Mg-deficient leaves and chaperonin precursor (R34 and 56) in Mg-deficient roots were represented by more than one spot (Tables 1 and 2). This might reflect isozymes or PTMs of a single protein [18].

\section{Proteins involved in carbohydrate and energy metabolism}

A crucial role of $\mathrm{Mg}$ is its involvement in the export of carbohydrates from source to sink sites. The accumulation of sugars in source leaves, an early symptom of $\mathrm{Mg}$ - 
Table 2 List of differentially expressed proteins identified using MALDI-TOF/TOF-MS in magnesium (Mg)-deficient Citrus sinensis roots

\begin{tabular}{|c|c|c|c|c|c|c|c|}
\hline Spot no. ${ }^{a}$ & Accession no. ${ }^{b}$ & Protein identity & Organism & MW (kDa) & $\mathrm{MP} / \mathrm{SC}$ & Score & Ratio $^{c}$ \\
\hline \multicolumn{8}{|c|}{ Carbohydrate and energy metabolism } \\
\hline R85 & gi|255579310 & Pyruvate decarboxylase, putative & Ricinus communis & 65.33 & $11 / 99$ & 204 & 0.062 \\
\hline R95 & gi|332195235 & Phosphoglycerate kinase & Arabidopsis thaliana & 49.91 & $17 / 92$ & 110 & 0.235 \\
\hline R83 & gi|710400 & Pyruvate dehydrogenase E1 alpha subunit & A. thaliana & 43.00 & $16 / 93$ & 56 & 3.440 \\
\hline R38 & gi|951369 & Ferredoxin NADP reductase & Pisum sativum & 10.82 & $8 / 101$ & 53 & 2.495 \\
\hline R111 & gi|222356610 & ATPase alpha subunit, partial (mitochondrion) & Afrothismia gabonensis & 40.27 & $15 / 94$ & 210 & 2.279 \\
\hline R36 & gi|302835814 & Adenylate kinase & Volvox carteri $f$. nagariensis & 25.89 & $11 / 78$ & 60 & 2.446 \\
\hline R120 & gi|33149683 & Alcohol dehydrogenase & Dianthus caryophyllus & 41.23 & $8 / 101$ & 287 & 2.764 \\
\hline R84 & gi|327555177 & Beta-amylase 8 & $\begin{array}{l}\text { Hordeum vulgare subsp. } \\
\text { vulgare }\end{array}$ & 51.37 & $17 / 93$ & 57 & 3.121 \\
\hline R121 & gi|11066213 & Hexokinase & Citrus sinensis & 54.02 & $14 / 93$ & 253 & 6.019 \\
\hline \multicolumn{8}{|c|}{ Protein metabolism } \\
\hline R1 & gi|255584432 & Proteasome subunit alpha type, putative & R. communis & 25.99 & $11 / 97$ & 190 & 100 \\
\hline R11 & gi|255620897 & Zinc metalloprotease, putative & R. communis & 17.94 & 9/99 & 57 & 3.011 \\
\hline R13 & gi|255543801 & Cysteine protease, putative & R. communis & 41.04 & $7 / 103$ & 91 & 4.924 \\
\hline R35 & gi|332006674 & Putative S9 tyrosyl aminopeptidase & A. thaliana & 81.26 & $12 / 97$ & 73 & 100 \\
\hline R57 & gi|332006104 & Eukaryotic translation initiation factor 3B-2 & A. thaliana & 82.12 & $16 / 93$ & 56 & 2.402 \\
\hline R34 & gi|806808 & Chaperonin precursor & P. sativum & 62.95 & $12 / 97$ & 131 & 0.180 \\
\hline R56 & gi|806808 & Chaperonin precursor & P. sativum & 62.95 & $19 / 90$ & 232 & 0.439 \\
\hline R2 & gi|124484511 & $\begin{array}{l}\text { Alpha chain of nascent polypeptide associated } \\
\text { complex }\end{array}$ & Nicotiana benthamiana & 21.91 & $10 / 47$ & 215 & 0.089 \\
\hline \multicolumn{8}{|c|}{ Stress responses } \\
\hline R14 & gi|23477636 & Grp94 (HSP) & Xerophyta viscosa & 92.90 & $24 / 84$ & 240 & 2.990 \\
\hline R70 & gi|227438123 & Disease resistance protein & $\begin{array}{l}\text { Brassica rapa subsp. } \\
\text { pekinensis }\end{array}$ & 81.89 & $19 / 90$ & 57 & 3.881 \\
\hline R53 & gi|399940 & Heat shock 70 kDa protein, mitochondrial & & 72.49 & $25 / 84$ & 330 & 0.319 \\
\hline R100 & gi|4028567 & Heat shock protein HSP26 & Triticum aestivum & 26.48 & $12 / 97$ & 66 & 0.325 \\
\hline \multicolumn{8}{|c|}{ Nucleic acid metabolism } \\
\hline R37 & gi|90403817 & RNA polymerase beta chain & Beaucarnea recurvata & 94.49 & $22 / 87$ & 72 & 0.481 \\
\hline R68 & gi|226528292 & Spliceosome RNA helicase BAT1 & Zea mays & 45.12 & 19/91 & 245 & 0.456 \\
\hline R82 & gi|33945882 & Transcription factor homolog BTF3-like protein & Lotus japonicus & 17.85 & $11 / 98$ & 242 & 0.272 \\
\hline \multicolumn{8}{|c|}{ Cell wall and cytoskeleton metabolism } \\
\hline R55 & gi|255115691 & Actin 1 & Boehmeria nivea & 41.64 & $19 / 90$ & 245 & 5.833 \\
\hline R69 & gi|71386188 & Villin 3 & Medicago sativa & 20.31 & $5 / 104$ & 123 & 3.134 \\
\hline R101 & gi|225454452 & Tubulin gamma-1 chain & Vitis vinifera & 53.25 & $12 / 97$ & 104 & 2.600 \\
\hline \multicolumn{8}{|c|}{ Lipid metabolism } \\
\hline R54 & gi|1117793 & Lipoxygenase & Solanum tuberosum & 99.60 & $14 / 95$ & 65 & 2.074 \\
\hline R99 & gi|870726 & Biotin carboxylase subunit & Nicotiana tabacum & 58.35 & $28 / 80$ & 419 & 0.289 \\
\hline \multicolumn{8}{|c|}{ Other and unknown biological processes } \\
\hline R3 & gi|30017553 & Unknown protein, 5'-partial & Oryza sativa Japonica Grou & 10.38 & $5 / 104$ & 46 & 2.086 \\
\hline R12 & gi|296086893 & Unnamed protein product & Vitis vinifera & 9.09 & $7 / 101$ & 55 & 0.278 \\
\hline
\end{tabular}

MP/SC: Number of matched peptides/sequence coverage percentage; MW: Theoretical molecular weigh;

${ }^{a}$ : Spot number corresponds to the 2-DE gel in Figure 4.

${ }^{b}$ : gi number is from $\mathrm{NCBI}$ database of matched protein.

c: Ratio means the ratio of Mg-deficiency to control; 0 means protein spots were only detected in control roots; 100 means protein spots were only detected in the Mg-deficient roots. 


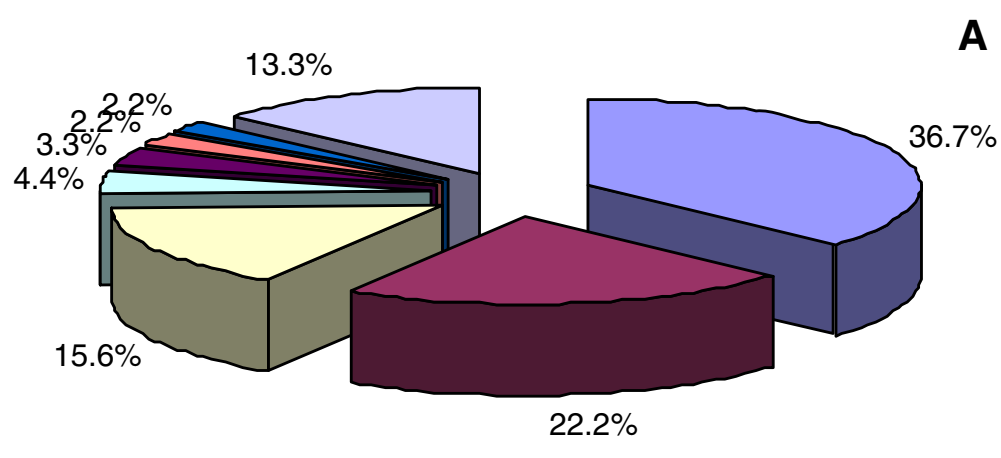

$\square$ Carbohydrate and energy metabolism

$\square$ Protein metabolism

$\square$ Stress responses

$\square$ Nucleic acid metabolism

$\square$ Cell wall and cytoskeleton metabolism

$\square$ Cell transport

$\square$ Lipid metabolism

$\square$ Other and unknown biological processes

\section{B}

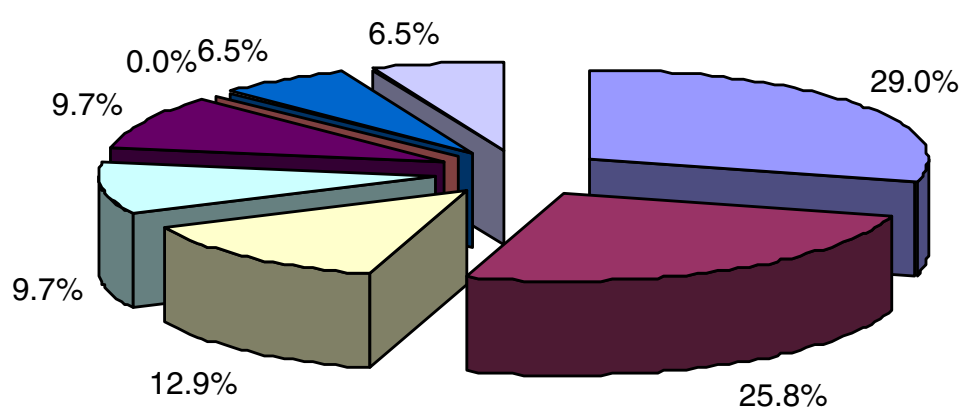

Figure 5 Functional classification of the differentially expressed protein spots in leaves (A) and roots (B).

deficiency, usually precedes the decreases in photosynthetic rate and Chl concentration $[2,5,10]$. The accumulation of sugars in leaves may repress the expression of genes that encode photosynthetic enzymes, thus decreasing Chl concentration and photosynthetic capacity [19]. Therefore, these proteins involved in photosynthesis and carbohydrate metabolism and related biological processes might be altered under Mg-deficiency. As expected, many differentially expressed proteins related to carbohydrate and energy metabolism were found in Mg-deficient leaves (Table 1 and Additional file 2). Our finding that $\mathrm{Mg}$-deficiency decreased the abundances of Rubisco (L118) and Rubisco activase (L20, 24, 26, 31, 35, 51 and 52) (Table 1) agrees with the report that Mg-deficiency reduced the activities of Rubisco and Rubisco activase and the expression levels of genes encoding Rubisco large subunit (rbcL), Rubisco small subunit (rbcS), and Rubisco activase subunit (rca) in spinach (Spinacia oleracea) leaves [20]. Mate et al. [21] reported that transgenic tobacco (Nicotiana tabacum) plants expressing an antisense gene encoding Rubisco activase reduced $\mathrm{Ru}-$ bisco carbamylation, hence impairing photosynthesis. Two studies with logan (Dimocarpus longana [22] and flowering Chinese cabbage (Brassica campestris) [23] revealed that Mg-deficiency-induced inhibition of photosynthesis might be associated with both reduced carboxylation efficiency and lower rate of ribulose-1,5-bisphosphate regeneration. Oxygen evolving enhancer proteins (OEEs) consist of three subunits, OEE 1 (33 kDa), OEE $2(23 \mathrm{kDa})$ and OEE 3 $(16 \mathrm{kDa})$. These are nuclear-encoded chloroplast proteins, and peripherally bound to photosystem II (PSII) on the luminal side of the thylakoid membrane. OEE1 is the most important protein for oxygen evolution and PSII stability. Mg-deficiency greatly decreased the level of OEE1 in leaves (L48, Table 1). This means that Mg-deficiency might impair the stability of oxygen evolution and PSII, as found on Mgdeficient C. sinensis and C. grandis [5]. In addition, Mgdeficient leaves had lower level of photosynthetic electron transfer-like protein (L115, Table 1), which agrees with the 


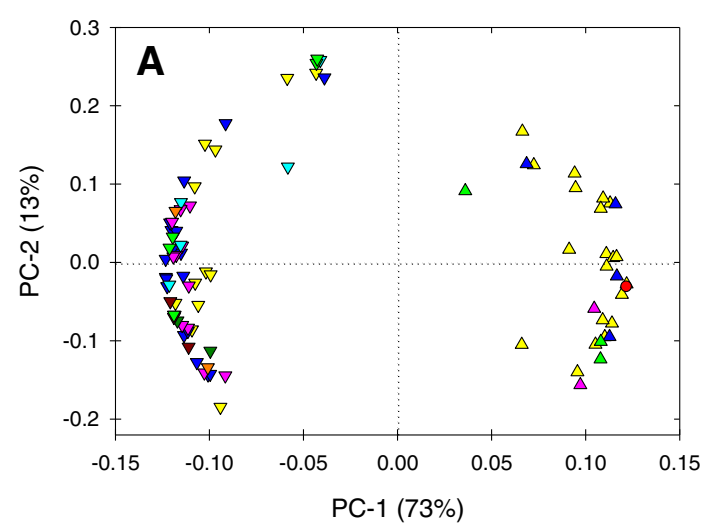

$\triangle$ Control

$\nabla \quad$ Mg-deficiency

$\nabla \quad$ Carbohydrate and energy metabolism

$\nabla$ Protein metabolism

$\nabla$ Stress responses

$\nabla \quad$ Nucleic acid metabolism

$\nabla$ Cell transport

$\nabla \quad$ Lipid metabolism

$\nabla$ Cell wall and cytoskeleton metabolism

$\nabla$ Other and unknown biological processes

- Mg

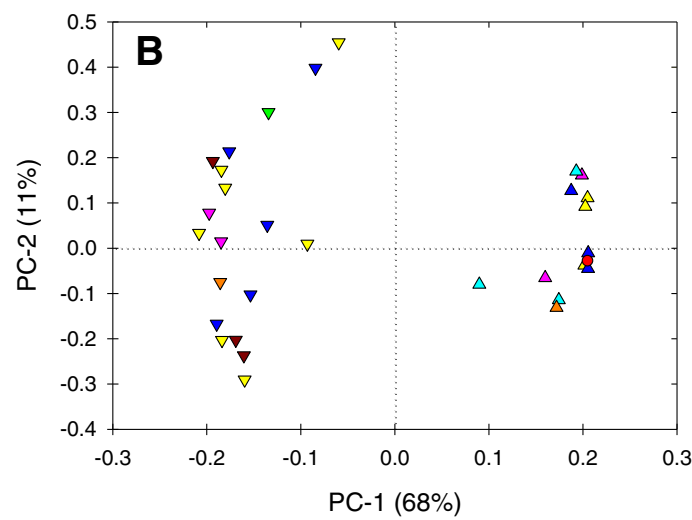

$\triangle$ Control

$\nabla$ Mg-deficiency

$\nabla \quad$ Carbohydrate and energy metabolism

$\checkmark$ Protein metabolism

$\nabla$ Stress responses

$\triangle \quad$ Nucleic acid metabolism

$\checkmark$ Cell wall and cytoskeleton metabolism

$\nabla \quad$ Lipid metabolism

$\nabla \quad$ Other and unknown biological processes

Mg

Figure 6 PCA loading plots of differentially expressed proteins in Mg-deficient leaves (A) and roots (B).

report that $\mathrm{Mg}$-deficiency decreased photosynthetic electron transport by impairing the whole photosynthetic electron transport chain from the PSII donor side up to PSI, thus decreasing Citrus leaf $\mathrm{CO}_{2}$ assimilation [5]. Hajirezaei et al. [24] reported that a small decrease in the activity of FNR by antisense RNA led to decreases in photosynthetic rate and NADPH level, and increases in the extent of $\mathrm{Q}_{\mathrm{A}}$ reduction and NADP level, and concluded that FNR was one of the rate-limiting steps in photosynthesis and FNR-deficiency-induced inhibition of photosynthesis was caused by impairment of FNRmediated electron transfer from reduced ferredoxin to NADP. As shown in Table 1, the level of putative FNR (L119) decreased in Mg-deficient leaves. This means that FNR activity might be downregulated by Mg-deficiency, thus impairing the photosynthetic electron transfer and increasing the extent of $\mathrm{Q}_{\mathrm{A}}$ reduction, and hence inhibiting photosynthesis. Palatnik et al. [25] demonstrated that FNR-deficient plants were particularly prone to photoinhibitory damage and photooxidative injury. All these results agree the report that $\mathrm{Mg}$-deficiency decreased $\mathrm{CO}_{2}$ assimilation, and increased the extent of $\mathrm{Q}_{\mathrm{A}}$ reduction and the concentration of malondialdehyde (MDA) in Citrus leaves [5].
The reduction of 3-phosphoglycerate to triose phosphate, which is reversibly catalyzed by two chloroplast enzymes [i.e. NADP-glyceraldehyde-3-phosphate dehydrogenase (GAPDH) and phosphoglycerate kinase (PG $\mathrm{K})$ ], is a crucial step in photosynthesis linking the photochemical events of the thylakoid membranes with the carbon metabolism of the photosynthetic carbon-reduction cycle in the stroma. Price et al. [26] showed that antisense transgenic plants with severely reduced chloroplast GAPDH activity were not photoinhibited despite the continuous presence of a large thylakoid proton gradient in the light, and that the electron-transport chain did not become over-reduced due to a shortage of NADP despite the downregulation of photosynthetic electron transport due to the build-up of a large proton gradient. The observed lower level of GAPDH B subunit (L114, Table 1) might be helpful to lessen photoinhibition and the overreduction of photosynthetic electron transport, thus lowering photooxidative damage caused by Mg-deficiency. In addition, Mg-deficiency decreased leaf abundance of PGK (L80, 93 and 94, Table 1). Therefore, the reduction of 3phosphoglycerate to triose phosphate might be decreased in Mg-deficient leaves due to lower activities of chloroplast GADPH and PGK. 


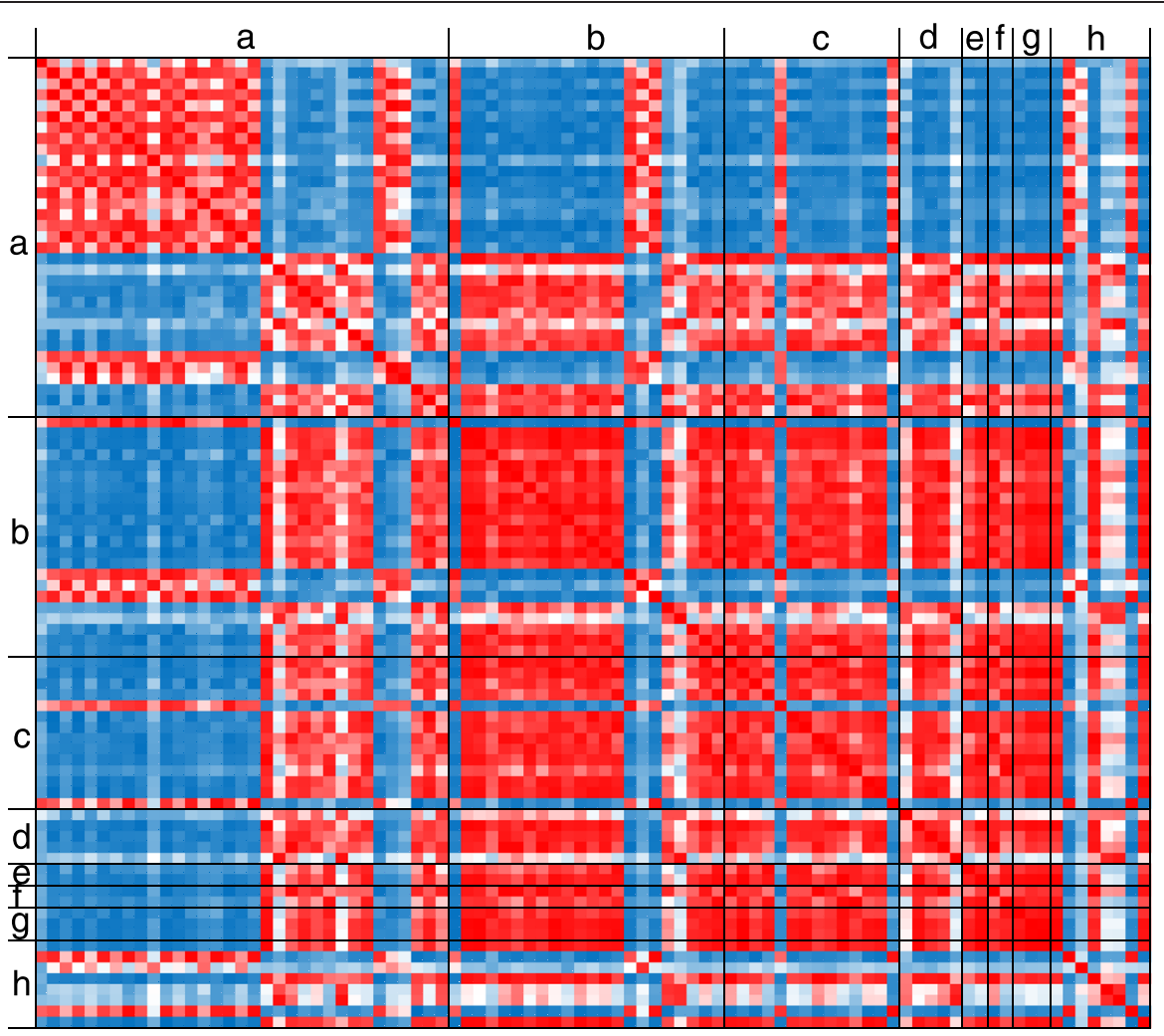

A

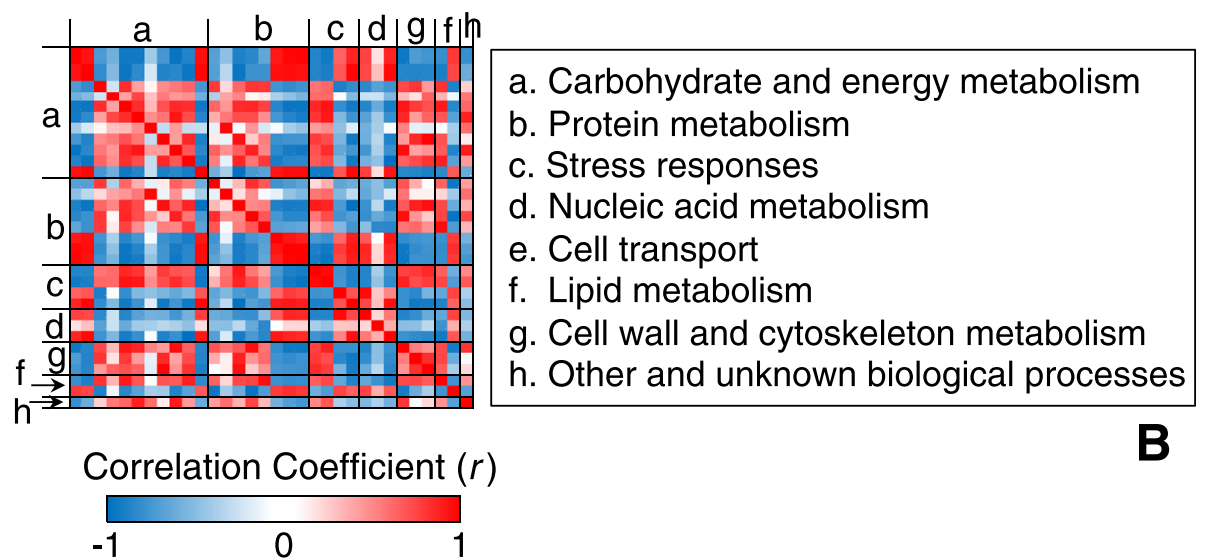

Figure 7 Pearson correlation coefficient matrix for the differentially expressed protein spots in Mg-deficient leaves (A) and roots (B). Red and blue colors indicated positive and negative correlation between the differentially expressed proteins.

Mg-deficiency also reduced leaf levels of putative carbonic anhydrase (L106), triosephosphate isomerase (L44), fructose-bisphosphate aldolase, class I (L108) and putative chloroplastic lactoylglutathione lyase (L67) (Table 1). Carbonic anhydrase, which reversibly catalyzes the interconversion of $\mathrm{CO}_{2}$ and $\mathrm{HCO}_{3}^{-}$, is a major protein constituent of the $\mathrm{C}_{3}$ higher plant chloroplast. Stimler et al. [27] showed that stomatal response was mediated by carbonic anhydrase, and that $\mathrm{H}_{2} \mathrm{~S}$ formed in the mesophyll via the reaction of carbonyl sulfide and water with carbonic anhydrase was involved in the stomatal response. The observed lower abundance of carbonic anhydrase means that its activity might be downregulated in Mg-deficient leaves, thus decreasing the stomatal conductance (Figure 2B). However, in addition to stomatal factor, non-stomatal factors such as photosynthetic inhibition also contributed to the lower $\mathrm{CO}_{2}$ assimilation in Mg-deficient leaves, as indicated by the increased intercellular concentration (Figure 2C). Ito 


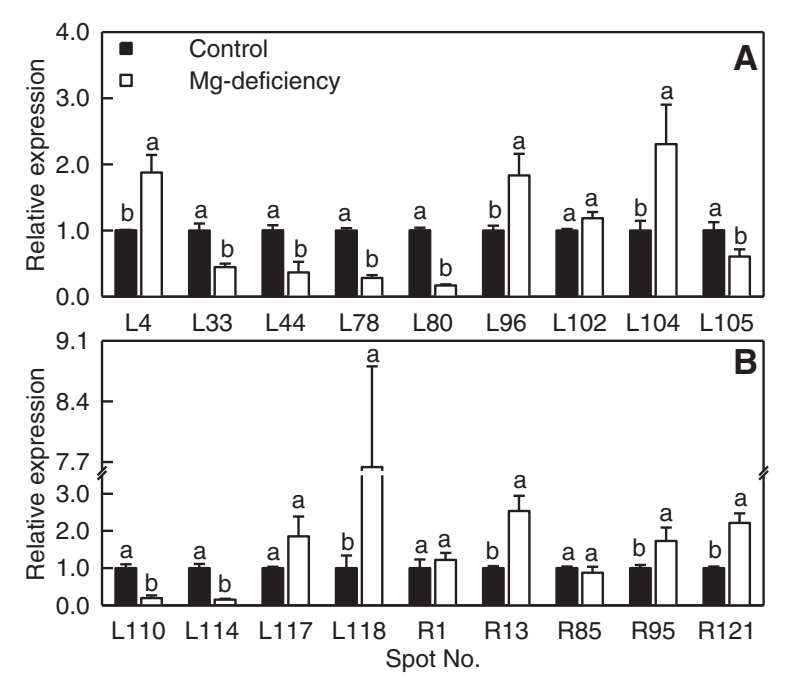

Figure 8 Relative expression of 13 genes from leaves and of five genes from roots. (A) Relative expression of nine leaf genes encoding cysteine proteinase (L4); ATP synthase CF1 alpha subunit, chloroplastic (L33), triosephosphate isomerase (L44), Cu/Zn superoxide dismutase (L78), phosphoglycerate kinase (L80), ascorbate peroxidase (L96), S-adenosylmethionine synthetase (L102), aconitate hydratase 3 (L104), nucleoside diphosphate kinase, putative (L105). (B) Relative expression of four leaf genes encoding ATYKT62 (L110), glyceraldehyde-3-phosphate dehydrogenase B subunit (L114), alcohol dehydrogenase (L117), and ribulose 1,5-bisphosphate carboxylase, partial (L118), and five root genes encoding proteasome subunit alpha type, putative (R1), cysteine protease, putative (R13), pyruvate decarboxylase, putative (R85), phosphoglycerate kinase (R95), and hexokinase (R121). Bars represent means $\pm \mathrm{SE}(n=3)$. Different letters above the bars indicate a significant difference at $P<0.05$. All the values were expressed relative to the control leaves or roots.

et al. [28] showed that triosephosphate isomerase and putative plastidic aldolase were inactivated by oxidized glutathione (GSSG) and reactivated by reduced glutathione (GSH). This agrees with the report that Mg-deficient Citrus leaves had increased GSSG concentration, but decreased GSH level [5]. Haake et al. [29] reported that a moderate decrease of plastidic aldolase activity led to a decrease in photosynthesis in antisense transgenic potato plants. Lactoylglutathione lyase (also known as glyoxalase I) catalyzes the formation of S-d-lactoylglutathione in the presence of glutathione and methylglyoxal, a cytotoxic compound produced spontaneously under physiological conditions from the glycolysis and photosynthesis intermediates glyceraldehyde-3-phosphate and dihydroxyacetone phosphate. Besides detoxification of methylglyoxal, the glyoxalase system could also play a role in oxidative stress tolerance by recycling GSH and maintaining glutathione homeostasis [30]. The observed lower level of putative chloroplastic lactoylglutathione lyase (L67) in Mg-deficient leaves (Table 1) agrees with our previous report that Mgdeficiency increased GSSG concentration and decreased
GSH concentration in Citrus leaves [5]. To conclude, Mgdeficiency decreased the levels of many proteins involved in photosynthesis including Rubisco, Rubisco activase, OEE1, photosynthetic electron transfer-like protein, FNR, aldolase, thus decreasing leaf photosynthesis.

We found that Mg-deficiency increased the abundances of NADP-malate dehydrogenase (L81), putative succinate dehydrogenase (SDH, L89) and aconitate hydratase (ACO) 3 (L104) in C. sinensis leaves (Table 1), which agrees with our data that $\mathrm{Mg}$-deficient leaves had higher rate of dark respiration (Figure 2E) and the report that the activities of enzymes related to glycolysis and TCA cycle were enhanced in Mg-deficient C. sinensis leaves [8]. NADPmalate dehydrogenase is the key enzyme in the malate/ oxalacetate shuttle, which is the major machinery for the transport of excess reducing equivalents generated in chloroplasts to mitochondria [31]. NADP-malate dehydrogenase converts oxalacetate to malate using NADPH, facilitating the regeneration of the electron acceptor NADP in the chloroplasts, particularly when $\mathrm{CO}_{2}$ assimilation is restricted [32]. The observed higher level of NADP-malate dehydrogenase in Mg-deficient leaves might contribute to the transport of excess reducing equivalents from chloroplasts to mitochondria and the regeneration of chloroplast NADP, thus preventing oxidative damage and enhancing the tolerance of plant to Mg-deficiency. Previous study showed that antisense inhibition of the iron-sulphur subunit of SDH and ACO reduced the carbon flow through the TCA cycle, and enhanced the photosynthesis and stomatal conductance [33]. This agrees with our data that Mgdeficient leaves had increased dark respiration (Figure 2E), levels of SDH and ACO (Table 1), and decreased $\mathrm{CO}_{2}$ assimilation (Figure 2A) and stomatal conductance (Figure 2B). Also, the abundances of putative dihydrolipoamide succinyltransferase component of 2-oxoglutarate dehydrogenase (L112) related to TCA cycle, and 2-phospho-D-glycerate hydrolase (L72) and 2,3-bisphosphoglycerate-independent phosphoglycerate mutase 1 (L86) involved in glycolysis in leaves increased in response to Mg-deficiency (Table 1).

Our finding that Mg-deficient leaves had increased abundance of $\alpha$-amylase (L60, Table 1), a starch degrading enzyme agrees with the report that the activities of two starch degrading enzymes ( $\alpha$-amylase and starch phosphorylase) increased in $\mathrm{Mg}$-deficient spruce needles [34]. Thus, starch degradation might be upregulated in Mg-deficient C. sinensis leaves. However, Mg-deficiency had little influence on starch concentration in C. sinensis leaves [5]. This might be related to the fact that sucrose biosynthesis and export decreased in response to $\mathrm{Mg}$ deficiency [34]. Also, the upregulation of starch biosynthesis was not ruled out, because the abundance of ADP-glucose pyrophosphorylase catalytic subunit (L77) increased in Mgdeficient leaves. Thus, it is reasonable to assume that the 
rate of starch turnover in Mg-deficient leaves might be enhanced [34].

Mg-deficient leaves had lower levels of putative ATP synthase $\beta$ subunit (L61), ATP syntase $\gamma$ chain 2 (L65), chloroplastic ATP synthase CF1 $\alpha$ subunit (L33) and chloroplastic ATP synthase subunit $\alpha$ (L47) (Table 1). This means that ATP synthesis catalyzed by ATP synthase in Mg-deficient leaves might be decreased, which might provide an advantage to prevent energy surplus due to increased dark respiration and the generation of excess reducing equivalents in chloroplasts.

Adenosine kinase, which catalyzes the reaction: adenosine + ATP $\rightarrow$ AMP + ADP, is an essential component for maintaining purine nucleotide pools in Arabidopsis. It also contributes to cytokinin interconversion in Arabidopsis [35] and plays a key role in sustaining transmethylation reactions by serving as a coarse metabolic control to reduce the concentration of free adenosine in spinach and sugar beet (Beta vulgaris) cells during salt stress [36]. Our finding that the abundance of putative adenosine kinase (L40) in leaves increased in response to Mg-deficiency (Table 1) agrees with the report that adenosine kinase activity, protein and transcripts in spinach and sugar beet leaves were enhanced by salt stress [36].

Nucleoside diphosphate kinase (NDPK) is a ubiquitous housekeeping enzyme that maintains the intracellular levels of all (d)NTPs used in biosynthesis except for ATP. In plants, NDPK2 is known to regulate the expression of antioxidant genes. Transgenic potato, sweet potato and Arabidopsis plants overexpressing Arabidopsis NDPK2 had increased activities of antioxidant enzymes and enhanced tolerance to methylviologen, salt and temperature stresses [37,38]. Aldehydes, which lead to a rapid and excessive accumulation of ROS in plants, may be induced by various abiotic stresses. Alcohol dehydrogenase (ADH), which converts aldehydes into alcohols, is essential for plants to survive under anaerobic conditions. ADH gene and/or protein are induced by ABA, salt, desiccation, high and low temperatures in various plants. It has been suggested that the induction of ADH by these stresses may trigger a signal transduction cascade, which would lead to a decrease in membrane damage, through adapting plants to oxidative stress $[39,40]$. Therefore, the antioxidant capacity might be upregulated in Mg-deficient leaves due to the increased level of putative NDPK (L105) and ADH (L117), hence enhancing the Mg-deficiency tolerance. This agrees with our report that $\mathrm{Mg}$-deficient $C$. sinensis leaves had higher activities of ascorbate peroxidase (APX), superoxide dismutase (SOD), glutathione reductase (GR), dehydroascorbate reductase (DHAR) and guaiacol peroxidase (GPX) [5].

Unlike to leaves, Mg-deficiency decreased root respiration (Figure 2G) and the activities of enzymes related to glycolysis and TCA cycle [8]. As expected, Mg-deficiency decreased the abundances of putative pyruvate decarboxylase (R85) and PGK (R95) in roots. However, root level of pyruvate dehydrogenase E1 $\alpha$ subunit (R83) increased in response to Mg-deficiency (Table 2).

In contrast to leaf putative FNR (L119, Table 1), the level of root FNR (R38, Table 2) was increased by Mgdeficiency. In higher plants, there are two forms of FNR, a photosynthetic FNR and a heterotrophic FNR. Onda et al. [41] revealed that the interaction of root FNR with ferredoxin $(\mathrm{Fd})$ is crucial for an efficient electron flux of NADPH-FNR-Fd cascade, thus supporting Fd-dependent metabolism in non-photosynthetic organs. Xu et al. [42] showed that the abundance of a FNR precursor was reduced by $60 \%$ in the roots of null transformant (NT) plants, but maintained in transgenic lines expressing the adenine isopentenyl transferase gene under heat stress, and concluded that the maintenance of FNR level under heat stress could reflect a superior $\mathrm{N}$ assimilation capacity of the transgenic lines over the NT line that facilitates their growth under heat stress. Thus, the observed higher level of FNR (R38) in Mg-deficient roots (Table 2) might be an adaptive response.

The biosynthesis of ATP in Mg-deficient roots might be enhanced due to increased level of mitochondrial ATPase $\alpha$ subunit, partial (R111, Table 2). Adenylate kinase catalyses the reversible formation of ADP by the transfer of one phosphate group from ATP to AMP, thus equilibrating adenylates [43]. Thus, the increased abundances of the two proteins might be advantage to maintaining energy balance in Mg-deficient roots, when ATP production was reduced due to decreased respiration (Figure 2G). Like leaves, the level of root ADH (R120) increased in response to Mg-deficiency. Similar result has been obtained on Bdeficient C. sinensis roots [16].

Similar to leaf $\alpha$-amylase, the activity of $\beta$-amylase might be upregulated in Mg-deficient roots due to enhanced abundance of $\beta$-amylase 8 (R84, Table 2), thus increasing the breakdown of starch into sugars in roots. This agrees with our report that Mg-deficiency decreased the concentration of starch in Citrus roots [5].

Hexokinases (HXKs) phosphorylate glucose to produce glucose-6-phosphate, the first step of glycolysis. Our finding that Mg-deficient roots had higher level of HXK (R121) compared with controls (Table 2) agrees with the reports that HXKs contributed to the survival of acclimated maize root tips via hypoxic pretreatment by allowing the maintenance of a sustained glycolytic rate [44], and that OsHXK7 (Oryza sativa hexokinase 7), localized at the cytosol, was upregulated under sugar-starvation conditions but downregulated in response to high sugar treatments of the leaf tissues of rice [45], because $\mathrm{Mg}$ deficiency decreased or did not affect the concentrations of non-structural carbohydrates in C. sinensis roots [5]. Also, HXKs might act as a glucose sensor (regulatory 
function) and, through its catalytic activity, as a crucial regulator of ROS levels in plant organelles such as mitochondria and chloroplasts [46].

\section{Proteins involved in stress responses}

Because leaf $\mathrm{CO}_{2}$ assimilation decreased in response to Mg-deficiency (Figure 2A), less of the absorbed light energy was utilized in photosynthetic electron transport, particularly under high light. The excess absorbed photon flux can potentially lead to ROS production. Thus, ROS production might be enhanced in Mg-deficient leaves [5]. To minimize the cellular damage caused by ROS, plants have evolved an antioxidant system composed of antioxidants and antioxidant enzymes. As expected, the leaf levels of antioxidant enzymes (L50, 63, 78 and 96) increased in response to Mg-deficiency except for chloroplast $\mathrm{Cu} / \mathrm{Zn}$ SOD (L97) (Table 1). This agrees with the report that Mg-deficient Citrus leaves had higher or similar activities of antioxidant enxymes [APX, monodehydroascorbate reductase, DHAR, GR, SOD and GPX] except for catalase [5]. Aldo-keto reductases (AKR), which catalyze the reduction of aldehyde to alcohol, are effective detoxification of peroxidation-derived reactive aldehydes [47]. Transgenic tobacco plants overexpressing alfalfa or rice $A R K$ had enhanced tolerance against a variety of oxidative damages induced by methylviologen, UV-B irradiation, heavy metals, drought, heat treatment, osmotic and salt stresses [47-49]. The upregulation of the putative AKR (L74 and 103) in Mg-deficient leaves (Table 2) might contribute to the oxidative tolerance of leaves. In addition, $\mathrm{Mg}$-deficiency increased the leaf abundances of heat shock proteins (HSPs, L28, 39, 46 and 59, Table 1), which play a key role in protecting plants against stress by reestablishing normal protein conformation and thus cellular homeostasis, and stress-related protein (L76 and 90, Table 1). Based on these results, we concluded that proteins associated with stress-response functions were upregulated in Mg-deficient leaves. However, the level of late embryogenesis abundant (LEA) protein (L116) in leaves decreased in response to Mg-deficiency (Table 1).

Like to leaves, the levels of stress-responsive proteins [Grp94 (HSP, R14) and disease resistance protein (R70)] in roots increased in response to Mg-deficiency (Table 2). This agrees with the reports that B-deficiency increased the level of NB-ARC domain-containing disease resistance protein in C. sinensis roots [16], and that the abundance of Grp94 in Xerophyta viscosa plants increased in response to heat and dehydration [50]. However, the abundances of mitochondrial heat shock $70 \mathrm{kDa}$ protein (R53) and heat shock protein HSP26 (R100) were decreased in Mg-deficient roots (Table 2), which agrees with the studies that B-deficiency decreased the levels of several HSPs (HSP70, HSP70 family proteins, mitochondrial HSO70 2 and HSP10) in C. sinensis roots
[16] and the abundances of three HSPs in Lupinus albus roots [51].

\section{Proteins involved in protein metabolism}

Protein synthesis elongation factor $\mathrm{Tu}(\mathrm{EF}-\mathrm{Tu})$ plays a central role in the elongation phase of protein synthesis in bacteria and organelles including mitochondria and plastids in plants [52]. We found that the abundance of the putative enongation factor tu (L79) in leaves decreased in response to Mg-deficiency (Table 1), meaning that the biosynthesis of some proteins in plastids and mitochondria might be downregulated. This agrees with our results that the levels of many chloroplastic (L118, $20,26,31,51,52,24,48,115,33$ and 67) proteins was decreased by Mg-deficiency (Table 1), and that the concentration of total soluble proteins in leaves decreased in response to Mg-deficiency (Figure 2G). However, the levels of chloroplastic chaperonin precursor (L25), chloroplastic small ribosomal protein 4, partial (L71) and ribosomal protein S3 (L88) related to protein folding and biosynthesis were increased in Mg-deficient leaves (Table 1).

Plant proteases play key roles in maintaining strict protein quality control and degrading specific sets of proteins in response to environmental and developmental stimuli. The majority of the thousand or more proteins that are present in mitochondria are required to be imported from nuclear-encoded cytosolically synthesized precursors, and a number of peptidases are needed to remove the "transient" targeting information present on many, but not all, mitochondrial precursor proteins [53]. The upregulation of mitochondrial processing peptidase $\beta$ subunit (L109) in Mg-deficient leaves (Table 1) agreed with the increased requirement for removing the "transient" targeting information due to enhanced import resulting from the increased abundance of the putative mitochondrial import inner membrane translocase subunit Tim17/Tim22/Tim23 family protein (L87, Table 1). Ubiquitination, which serves as a versatile PTM, plays a key role in regulating plant response to abiotic stresses. It has been known that the F-box is a motif for ubiquitin dependent proteolysis in cell cycle regulation and signal transduction [54], and that the RING zinc-finger domain is essential for the function of ubiquitin E3 ligases [55]. The upregulation of F-box domain-containing protein (L41), putative F-box family protein, expressed (L8), putative F-box/kelch-repeat protein (L9) and putative RING zinc finger protein (L62) in Mg-deficient leaves (Table 2) means that leaf ubiquitination might be enhanced in response to Mg-deficiency. Also, the abundances of proteins (L4, 6, 45, 49 and 58) related to protein degradation increased in Mg-deficient leaves (Table 1). In conclusion, proteolysis might be enhanced in Mg-deficient leaves, thus lowering leaf concentration of total soluble proteins 
(Figure 2F). However, the abundances of leaf F2E2.12 (membrane-anchored ubiquitin-fold protein 6 precursor, L27) and putative skp1 protein [an essential component of the SCF (SKP1-CUL1-F-box protein) ubiquitin ligase complex, L98] decreased in response to Mg-deficiency (Table 1).

Amino acids are the structural units that make up proteins and also serve as precursors for many metabolites with multiple functions in plant growth and response to various stresses. All the four differentially expressed proteins (L75, 91, 102 and 113) involved in amino acid metabolism were upregulated in $\mathrm{Mg}$-deficient leaves (Table 1), meaning that the metabolism of amino acids might be upregulated in $\mathrm{Mg}$-deficient leaves. Glutathione S-transferases (GSTs), which catalyze the conjugation of cytotoxic metabolites with the GSH, are mainly involved in detoxifying oxidative-stress metabolites. Glutamine synthetase (GS) catalyses the critical incorporation of inorganic ammonium into the amino acid glutamine. In plants, two types of GS isozymes, located in the cytosol (GS1) and in the chloroplast (GS2) have been found. Transgenic plants overexpressing GS1 or GS2 displayed enhanced tolerance to water or salt stress, respectively [56,57]. Methylation induced by abiotic stress has been supposed to be linked with the numerous biochemical pathways involved in acclimatization and stress response in plants [58]. S-adenosylmethionine is an important methyl donor for numerous transmethylation reactions. $\mathrm{S}$-adenosylmethionine synthase is a crucial enzyme that directs the flux of methione to S-adenosylmethionine. These results indicate that the upregulation of amino acid metabolism in Mg-deficient leaves might be involved in the adaption of $\mathrm{Mg}$-deficient plants.

Proteolytic cleavage of proteins by proteases is not limited to the total degradation of mature proteins to free amino acids, but also is relevant for modification and maturation of proteins. Like to leaves, Mg-deficiency increased the abundances of root proteins (R1, 11, 13 and R35) involved in proteolysis (Table 2). However, there was no significant difference in total soluble protein concentration between Mg-deficient and control roots (Figure 2H). This implies that the Mg-deficiency-induced increase in protease levels may be mainly involved in modification and maturation of proteins or that the biosynthesis is enhanced in Mg-deficient roots. The upregulation of proteases in $\mathrm{Mg}$-deficient roots might be an adaptive response of plants to $\mathrm{Mg}$-deficiency through maintaining the protein complexes and/or the recycling of $\mathrm{N}$.

The eukaryotic translation initiation factor 3 (eIF3) has multiple roles during the initiation of translation of cytoplasmic mRNAs. The classic functions ascribed to eIF3 include: (a) facilitating the charging of the $40 \mathrm{~S}$ ribosomal subunit with the ternary complex; $(b)$ bridging between the $40 \mathrm{~S}$ ribosomal subunit and the eIF4G subunit of the cap-binding complex, eIF4F; and (c) inhibiting the association of $40 \mathrm{~S}$ and $60 \mathrm{~S}$ ribosomal subunits [59]. The upregulation of eIF 3B-2 (R57) in Mg-deficient roots (Table 2) might contribute to the translatability of cytoplasmic mRNAs, thus maintaining the level of cytoplasmic proteins, which agrees with our result that $\mathrm{Mg}$-deficiency did not significantly affect root concentration of total soluble proteins (Figure 2F). However, the levels of root proteins (R2, 34 and 56) involved in protein folding and biosynthesis were decreased by Mg-deficiency.

\section{Proteins involved in nucleic acid metabolism}

The downregulation of RNA polymerase $\beta$ chain (R37), spliceosome RNA helicase BAT1 (R68) and transcription factor homolog BTF3-like protein (R82) in Mg-deficient roots (Table 2) agrees with our report that all 60 differentially expressed proteins related to nucleic acid metabolism were reduced in B-deficient $C$. sinensis roots except for argonaute family protein [16]. This indicates that the synthesis of RNA might be inhibited in Mg-deficient roots. By contrast, the abundances of all the four altered proteins (L5, 17, 22 and 73) related to nucleic acid metabolism in leaves increased in response to Mg-deficiency (Table 1), meaning that the metabolism of nucleic acid might be upregulated in $\mathrm{Mg}$-deficient leaves.

DEAD box RNA helicases are prominent candidates for RNA chaperones because these proteins can use energy derived from ATP hydrolysis to actively disrupt misfolded RNA structures so that correct folding can occur, and play important roles in plant stress responses [60,61]. Transgenic Arabidopsis plants overexpressing a rice gene OsBIRH1, which encodes a DEAD-box RNA helicase protein, showed enhanced disease resistance against Alternaria brassicicola and Pseudomonas syringae, and increased tolerance to oxidative stress and elevated expression levels of oxidative defense genes [61]. The upregulation of DEAD box RNA helicases (L73) in Mg-deficient leaves (Table 1) might be an adaptive response of plants to Mg-deficiency. In nonplant systems, the splicing of group-II introns is mediated by proteins encoded within the introns themselves (known as "maturases"), whereas only a single maturase ORF (matR) has retained in the mitochondrial genomes in plants. Interestingly, higher plant genomes contain four maturase-related genes, which exist in the nucleus as self-standing ORFs. Recently, Keren et al. [62] showed that AtnMat2, a nuclear-encoded maturase, was required for splicing of group-II introns in Arabidopsis mitochondria. In another study, Keren et al.[63] observed that nMAT1 functions were required for mitochondrial biogenesis and that nMat1 mutants displayed growth and developmental defect phenotypes and accumulated high levels of ROS, concluding that nMAT1 was essential for mitochondrial complex I assembly and function. Thus, the observed higher level of 
maturase, partial (L5, Table 1) in Mg-deficient leaves might be an adaptive response.

\section{Proteins involved in cell wall and cytoskeleton metabolism}

$\mathrm{Ca}$, a constituent of the cell wall, plays a key role in determining the structural rigidity of the cell wall. Also, Ca is a regulator that can exert multiple effects on the structure and dynamics of the actin cytoskeleton [64]. It has been well known that high rhizosphere concentration of $\mathrm{Mg}$, relative to $\mathrm{Ca}$, is inhibitory to the absorption of $\mathrm{Ca}$ and vice versa. Therefore, the concentration of $\mathrm{Ca}$ in Mg-deficient plant tissues should be enhanced. Indeed, Mg-deficiency increased the concentration of $\mathrm{Ca}$ in rough-lemon (Citrus volkameriana) leaves [65]. Based on these results, it is reasonable to assume that the $\mathrm{Mg}$ deficiency-induced increase in $\mathrm{Ca}$ concentration might be responsible for the enhanced abundances of myosin class 11-1 (L16), UGT1 (UDP-glucosyltransferase, L21) and pollen coat oleosin-glycine rich protein (L107) involved in cell wall and cytoskeleton metabolism in $\mathrm{Mg}$ deficient leaves (Table 1). Similarly, the abundances of root actin 1 (R55), villin 3 (R69) and tubulin $\gamma-1$ chain (R101) were upregulated by Mg-deficiency (Table 2), which is in agreements with the report that Mg-deficiency led to enhanced suberization in endodermis and hypodermis of corn roots [66]. The upregulation of proteins related to cell wall and cytoskeleton metabolism in $\mathrm{Mg}$ deficient roots and leaves might be an adaptive response of plants to Mg-deficiency.

\section{Proteins involved in cell transport}

Proteins that reside in endomembrane organelles, or that are secreted from the cell, reach their sites of function by transport of the endomembrane system [67]. The translocase of the inner membrane (TIM) is a complex of proteins found in the inner membrane of the mitochondria and plays a pivotal role in protein import, which is important to cope with stress [53]. The observed higher level of the putative mitochondrial import inner membrane translocase subunit Tim17/Tim22/Tim23 family protein (L87) in $\mathrm{Mg}$-deficient leaves (Table 1) can be explained by the fact that mitochondria are the center of oxygen sensing. Under Mg-deficiency, high protein import might be required for the increased ROS detoxification [5], thus requiring high activity of the TIM protein complex [68]. SNAREs are core proteins for vesicle fusion and can be categorized into two types: SNAREs on the vesicle are called v-SNAREs, while SNAREs on the target membrane are called t-SNAREs. AtYKT61 and AtYKT62, two tSNARES, are essential for membrane fusion mediated by either SYP41 or STP62 $[67,69]$. The upregulation of the two proteins means that the transport of proteins might be enhanced in Mg-deficient roots.

\section{Proteins involved in lipid metabolism}

Sato-Izawa et al. [70] revealed that the inositol-1,4,5-trisphosphate 5-phosphatase, an enzyme probably involved in phosphoinositide signaling, was required for many essential cellular functions, such as cytoskeleton organization, endocytosis and vesicular trafficking in eukaryotes. Perera et al. [71] showed that transgenic Arabidopsis plants expressing the type 1 inositol-1,4,5-trisphosphate 5-phosphatase had enhanced drought tolerance and altered ABA signaling. Cytochrome P450s (CytoP450s), a superfamily of ubiquitous heme-containing mixed-function monooxygenases proteins, play a key role in biotic and abiotic stresses [72]. In Arabidopsis, at least five of the 29 CytoP450s are induced by abiotic and biotic stresses including Alternaria brassicicola or Alternaria alternata, paraquat, rose bengal, UV-C stress, heavy metal stress $\left(\mathrm{CuSO}_{4}\right)$, mechanical wounding, drought, high salinity, low temperature or hormones [73]. Transgenic tobacco and potato plants expressing CytP450 with increased monooxygenase activity tolerated better oxidative stress after herbicide treatment [72]. Therefore, the observed higher level of putative type 1 inositol-1,4,5-trisphosphate 5-phosphatase CVP2 (L43, Table 1) and putative CytoP450 (L19, Table 1) might contribute to $\mathrm{Mg}$-deficiency tolerance of plants.

We found that the abundance of root lipoxygenase (LOX, R54) increased in response to Mg-deficiency (Table 2), which is in agreement with the report that the level of LOX 2 was enhanced in B-deficient $C$. sinensis roots [16]. LOX, which catalyses the oxidation of $\alpha$-linolenic acid into either 9- or 13-hydroperoxy-octadecatrienoic acids, or a mixture of both, is one of the key enzymes responsible for the biosynthesis of jasmonates, which are ubiquitously occurring lipid-derived compounds with signal functions in plant responses to abiotic and biotic stresses [74]. $\mathrm{Hu}$ et al. [75] demonstrated that TomloxD, a tomato 13-LOX gene, was involved in endogenous jasmonate synthesis and tolerance to biotic and abiotic stress. Therefore, both jasmonate biosynthesis and level might be increased in Mg-deficient roots, thus enhancing plant $\mathrm{Mg}$-deficiency tolerance. This inference is also supported by the observation that the expression levels of two genes encoding MYC2, which is a jasmonate-dependent transcription factor and LOX2, which is an enzyme involved in jasmonate biosynthesis $[76,77]$ in roots increased in response to $\mathrm{Mg}$-deficiency (Additional file 2). Thus, jasmonate signaling might be involved in the responses of Citrus roots to Mg-deficiency. However, the expression of the gene encoding ZIM/tifydomain (JAZ/TIFY), which is the co-repressor of MYC2 that is ubiquitinilated upon activation of jasmonate signaling cascade [78], did not change in Mg-deficient citrus roots (Additional file 2).

The plastid acetyl-coenzyme A carboxylase, which catalyzes the first committed step of fatty acid synthesis, is 
present as a heteromeric complex of at least four different protein subunits: the biotin carboxylase, the biotin carboxyl carrier protein, and the $\alpha$ and $\beta$ subunits of the carboxyltransferase in most plants. Transgenic tobacco plants with less than $25 \%$ of wild-type biotin carboxylase levels displayed severely retarded growth when grown under low-light conditions and a $26 \%$ lower leaf fatty acid concentration than wild-type plants [79]. Thus, the biosynthesis of fatty acids in $\mathrm{Mg}$-deficient roots might be elevated due to enhanced level of biotin carboxylase subunit (R99, Table 2).

\section{Other proteins}

Ent-kaurene is a tetracyclic hydrocarbon precursor for gibberellins (GAs) in plants. In higher plants, ent-kaurene is synthesized successively by copalyl diphosphate synthase (CPS) and ent-kaurene synthase (KS) from geranylgeranyl diphosphate (GGDP). A range of GA-deficient phenotypes of the ga1-3 and ga2-1 A. thaliana mutants (defective in CPS and KS, respectively) were restored to wild type, when fungal CPS/KS was overexpressed and targeted to plastids. The over-expressing plants emitted ent-kaurene into the headspace besides its accumulation in the plant body [80]. Fleet et al. [81] showed that transgenic Arabidopsis plants overexpressing AtCPS and AtKS led to increased ent-kaurene production but unchanged concentration of active GAs. Therefore, the upregulation of ent-kaurene synthase (L10) in Mg-deficient leaves (Table 1) does not necessarily imply that leaf concentration of GAs was enhanced by Mg-deficiency.

\section{Conclusions}

We first investigated the proteomic changes induced by long-term Mg-deficiency in C. sinensis leaves and roots using 2-DE. In Mg-deficient leaves, 59 upregulated and 31 downregulated proteins were isolated, while only 19 upregulated and 12 downregulated proteins in $\mathrm{Mg}$ deficient roots. This indicated that proteomes were more affected by long-term Mg-deficiency in the leaves than in the roots, which was further supported by our observation that the concentration of total soluble proteins was decreased by Mg-deficiency in leaves, but unaffected in roots. A potential regulatory network of Mg-deficiencyinduced responses in Citrus leaves and roots was proposed through the integration of the present results and available data in the literatures (Figure 9). Mg-deficiency led to decreased abundances of proteins (Rubisco, Rubisco activase, OEE1, photosynthetic electron transfer-like protein, FNR etc.) involved in photosyntheis, thus decreasing leaf $\mathrm{CO}_{2}$ assimilation. The adaptive responses of $C$. sinensis roots and leaves to Mg-deficiency might including several aspects: (a) improving leaf respiration and lowering root respiration, but increasing (decreasing) the levels of proteins related to ATP synthase in roots (leaves);

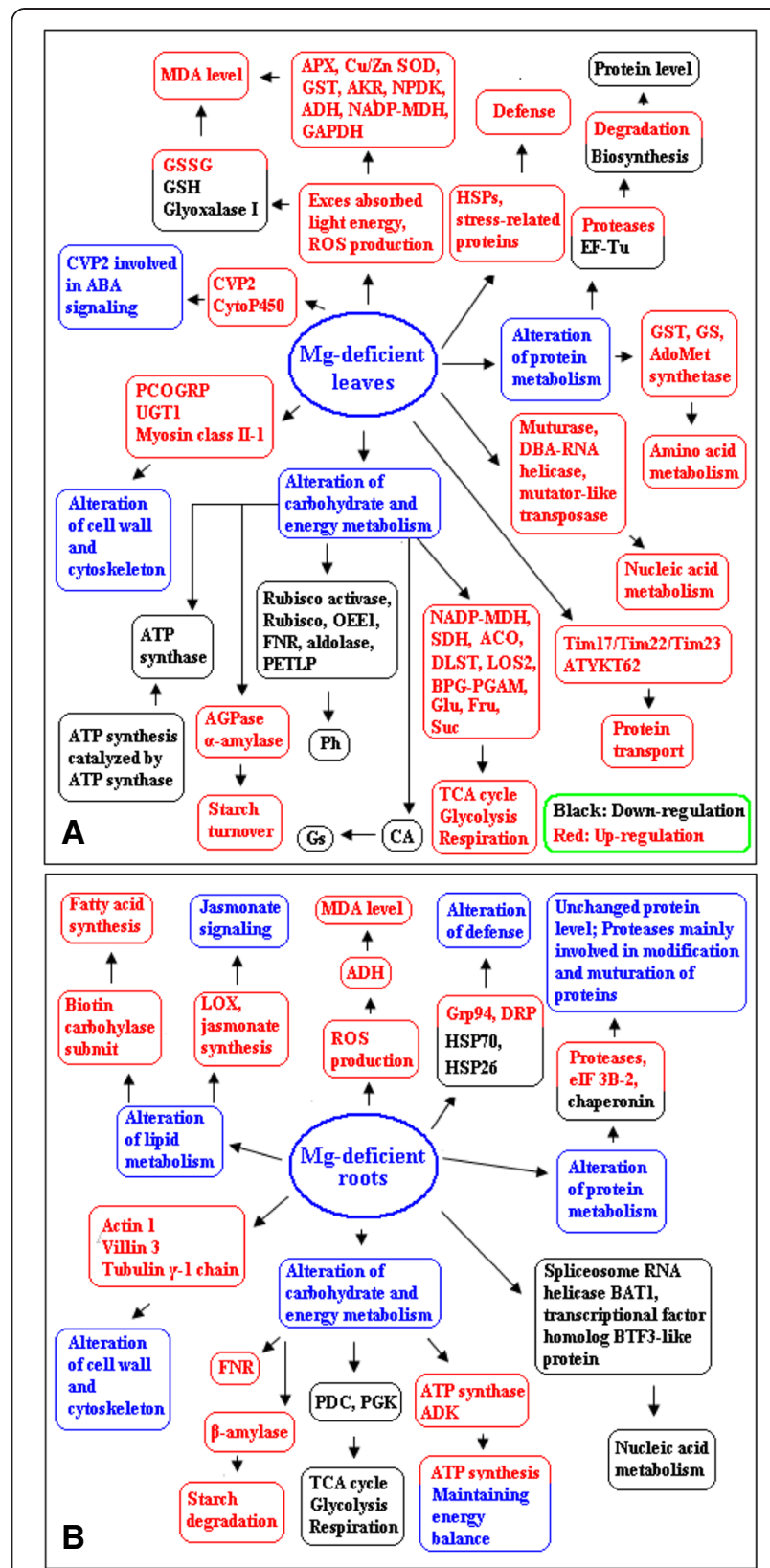

Figure 9 The potential regulatory network of Mg-deficiencyinduced responses in Citrus leaves (A) and roots (B). BPG-PGAM: 2,3-Bisphosphoglycerate-independent phosphoglycerate mutase 1; CVP2: Type I inositol-1,4,5-trisphosphate 5-phosphatase CVP2; DBA- RNA helicase: Dead box ATP-dependent RNA helicase; DLST: Dihydrolipoamide succinyltransferase component of 2-oxoglutarate dehydrogenase; DRP: Disease resistance protein; Fru: Fructose; Glu: Glucose; Gs: Stomatal conductance; LOS2: 2-Phospho-D-glycerate hydrolase; NADP-MDH: NADP-malate dehydrogenase; PCOGRP: Pollen coat oleosin-glycine rich protein; PDC: Pyruvate decarboxylase; PETLP: Photosynthetic electron transfer-like protein; Pn: Photosynthesis; Suc: Sucrose; Tim17/Tim22/Tim23: Mitochondrial import inner membrane translocase subunit Tim17/Tim22/Tim23 family protein. 
(b) enhancing the levels of proteins (such as APX, $\mathrm{Cu} / \mathrm{Zn}$ SOD, GST, AKR, NPDK and ADH) involved in ROS scavenging and other stress-responsive proteins (i.e. HSPs and stress-related proteins); (c) accelerating proteolytic cleavage of proteins by proteases, protein transport and amino acid metabolism; and $(d)$ upregulating the levels of proteins involved in cell wall and cytoskeleton metabolism. Therefore, our proteomic analysis provides an integrated view of the adaptive responses occurring in Mg-deficient leaves and roots of $C$. sinensis. As a first attempt, the present study will be useful for further investigating the roles of $\mathrm{Mg}$ in higher plants. It is worth noting that it may provide more data on Mg-deficiency in real Citrus orchards if we use grafted plants rather than C. sinensis seedlings as experimental materials, but it is difficult for us to compare the present data with the transcriptomic data obtained on Arabidopsis roots and leaves [12,13] and the physiological and biochemical data obtained on $C$. sinensis roots and leaves [5,8]. In the further study, we will investigate the effects of rootstocks on Mg-deficiencyresponsive proteomics using grafted citrus plants from different rootstock-scion combinations including both ownrooted scions and rootstocks as controls to obtain more knowledge on Mg-deficiency in real citrus orchards.

\section{Methods}

\section{Plant culture, Mg treatments and sampling}

The study was conducted from February to December, 2011 at Fujian Agriculture and Forestry University. Plant culture, Mg treatments, and sampling were performed according to Yang et al. [5]. Briefly, five-week-old seedlings of 'Xuegan' [Citrus sinensis (L.) Osbeck] were transplanted to $6 \mathrm{~L}$ pots containing sand. Seedlings, two per pot, were grown outdoors at Fujian Agriculture and Forestry University. Each pot was supplied with $500 \mathrm{~mL}$ of nutrient solution every other day. The nutrient solution contained the following macronutrients (in $\mathrm{mM}$ ): $\mathrm{KNO}_{3}, 2.5 ; \mathrm{Ca}$ $\left(\mathrm{NO}_{3}\right)_{2}, 2.5 ; \mathrm{KH}_{2} \mathrm{PO}_{4}, 0.5 ; \mathrm{MgSO}_{4}, 1$; micronutrients (in $\mu \mathrm{M}): \mathrm{H}_{3} \mathrm{BO}_{3}, 10 ; \mathrm{MnCl}_{2}, 2 ; \mathrm{ZnSO}_{4}, 2 ; \mathrm{CuSO}_{4}, 0.5 ;\left(\mathrm{NH}_{4}\right)$ ${ }_{6} \mathrm{Mo}_{7} \mathrm{O}_{24}, 0.065$; and Fe-EDTA, 20. Ten weeks after transplanting, each pot was supplied every other day until saturated with $\mathrm{Mg}$-deficient $\left(0 \mathrm{mM} \mathrm{MgSO}{ }_{4}\right)$ or $\mathrm{Mg}$-sufficient (1 $\mathrm{mM} \mathrm{MgSO}_{4}$ ) nutrient solution for 16 weeks. Sulfur (S) concentration was maintained at a constant level by adding equivalent moles of $\mathrm{Na}_{2} \mathrm{SO}_{4}$ in replace of $\mathrm{MgSO}_{4}$. At the end of the experiment, fully-expanded (about 7 weeks old) leaves from different replicates and treatments were used for all the measurements. Leaf discs $\left(0.608 \mathrm{~cm}^{2}\right.$ in size) were collected at noon under full sun and immediately frozen in liquid $\mathrm{N}_{2}$. Approximately 5 -mm-long root apices were frozen immediately in liquid $\mathrm{N}_{2}$ after they were excised from the same seedlings used for sampling leaves. Both leaf and root samples were stored at $-80^{\circ} \mathrm{C}$ until extraction.
Leaf, stem and root DW, and Mg concentration in leaves, stems and roots

At the end of the experiment, 9-10 plants per treatment from different pots were harvested. The plants were divided into leaves, stems and roots. The plant material was then dried at $70^{\circ} \mathrm{C}$ for $48 \mathrm{~h}$ and the DW measured. $\mathrm{Mg}$ concentration in leaves, stems and roots was determined by atomic absorption spectroscopy after digested with $1 \mathrm{~N} \mathrm{HCl}$ [82].

\section{Total soluble protein concentration in leaves and roots}

Total soluble proteins in leaves and roots were extracted with $50 \mathrm{mM} \mathrm{Na} 2 \mathrm{HPO}_{4}-\mathrm{KH}_{2} \mathrm{PO}_{4}(\mathrm{pH} 7.0)$ and $5 \%(\mathrm{w} / \mathrm{v})$ insoluble polyvinylpyrrolidone (PVPP), and measured according to Bradford [83] using bovine serum albumin (BSA) as standard.

\section{Leaf gas exchange and root and leaf respiration}

Measurements of leaf gas exchange were made with a CIRAS-2 portable photosynthesis system (PP systems, Herts, UK) at ambient $\mathrm{CO}_{2}$ concentration under a controlled light intensity of $1000 \mu \mathrm{mol} \mathrm{m}^{-2} \mathrm{~s}^{-1}$ between 10:00 and 11:00 on a clear day. During measurements, leaf temperature and vapor pressure deficit were $30.7 \pm 0.1^{\circ} \mathrm{C}$ and $2.2 \pm 0.1 \mathrm{kPa}$, respectively. Dark respiration was measured with a CIRAS-2 portable photosynthesis system on both control and Mg-deficient leaves at ambient $\mathrm{CO}_{2}$ concentration and an ambient temperature at darkness at gas exchange measurements.

Root respiration $\left(\mathrm{O}_{2}\right.$ consumption at $\left.25^{\circ} \mathrm{C}\right)$ was measured using Oxy-Lab system from Hansatech (Norfolk, UK) [84].

\section{Protein extraction for 2-DE}

Proteins were extracted from frozen roots and leaves using a phenol extraction procedure [16]. Briefly, about $1 \mathrm{~g}$ frozen samples were well ground in liquid $\mathrm{N}_{2}$ with a mortar and pestle. Four milliliter of ice-cooled buffer containing $100 \mathrm{mM}$ Tris- $\mathrm{HCl} \mathrm{pH} \mathrm{7.8,} 100 \mathrm{mM} \mathrm{KCl}$, $50 \mathrm{mM}$ L-ascorbic acid, 1\% (v/v) Triton X-100, 1\% (v/v) $\beta$-mercaptoethanol, and $1 \mathrm{mM}$ phenylmethylsulfonyl fluoride was added to the powder and gently pulverized. The mixture was allowed to thaw slowly on ice and then gently grounded for several minutes. The resulting suspension was transferred to a $10 \mathrm{~mL}$ tube, then an equal volume of Tris-phenol ( $\mathrm{pH}$ 8.0) was added. Before centrifuging at $13,000 \mathrm{~g}$ for $15 \mathrm{~min}$ at $4^{\circ} \mathrm{C}$, the mixture was thoroughly vortexed. The upper phenolic phase was transferred to a $50 \mathrm{~mL}$ Corning tube, then five volumes (about $20 \mathrm{ml}$ ) of $100 \mathrm{mM}$ ammonium acetate/methanol was added. After being blended upside down carefully, the mixture was stored at $-20^{\circ} \mathrm{C}$ overnight. The supernatant was removed carefully after centrifugation at $13,000 \mathrm{~g}$ for $15 \mathrm{~min}$ at $4^{\circ} \mathrm{C}$, then the protein pellets were 
resuspended in $25 \mathrm{~mL}$ of ice-cooled methanol for $2 \mathrm{~h}$ at $-20^{\circ} \mathrm{C}$. Protein pellets were collected by centrifugation at $13,000 \mathrm{~g}$ for $15 \mathrm{~min}$ at $4^{\circ} \mathrm{C}$, and then were resuspended in $25 \mathrm{~mL}$ of ice-cooled acetone containing $0.1 \%$ $\beta$-mercaptoethanol and kept at $-20^{\circ} \mathrm{C}$ for $2 \mathrm{~h}$. After centrifugation at $13,000 \mathrm{~g}$ for $15 \mathrm{~min}$ at $4^{\circ} \mathrm{C}$, the pellets were washed twice with $25 \mathrm{~mL}$ of ice-cooled acetone, and then dried by lyophilization and solubilized in lysis buffer [8 M urea, $2 \mathrm{M}$ thiourea, 4\% (w/v) 3-[(3-cholamidopropyl) dimethylammonio]-1- propanesulfonate (CHAPS), $2 \%(\mathrm{v} / \mathrm{v})$ pharmalyte $\mathrm{pH} 3-10$, and $20 \mathrm{mM}$ dithiothreitol (DTT)]. Sample protein concentration was assayed according to Bradford [83]. Three independent protein samples were extracted from three biological replicates for 2-DE.

\section{2-DE and image analysis}

Protein samples $(1.5 \mathrm{mg})$ were diluted with rehydration solution [8 M urea, $2 \mathrm{M}$ thiourea, $4 \%$ (w/v) CHAPS, $0.5 \%$ (v/v) IPG buffer, $13 \mathrm{mM}$ DTT, 0.002\% (w/v) bromophenol blue] to the total volume of $450 \mu \mathrm{L}$ and then applied to $24 \mathrm{~cm}$ Immobiline DryStrips with a linear $\mathrm{pH}$ gradient of 4-7 (GE Healthcare, Uppsala, Sweden) on the rehydration cassette overnight. The isoelectric focusing electrophoresis was carried out using a Ettan IPGphor (GE Healthcare, Uppsala, Sweden) at $200 \mathrm{~V}$ for $1.5 \mathrm{~h}, 500 \mathrm{~V}$ for $1.5 \mathrm{~h}$, $1,000 \mathrm{~V}$ for $2 \mathrm{~h}, 0.5 \mathrm{~h}$ to increase the voltage from $1,000 \mathrm{~V}$ to $8,000 \mathrm{~V}, 8,000 \mathrm{~V}$ for $5 \mathrm{~h}, 2 \mathrm{~h}$ to increase the voltage from $8,000 \mathrm{~V}$ to $10,000 \mathrm{~V}$ and then $1 \mathrm{~h}$ to decrease to $2,000 \mathrm{~V}$ until next step. Prior to sodium dodecyl sulphatepolyacrylamide gel electrophoresis (SDS-PAGE), the IPGstrips were subjected to $2 \times 20 \mathrm{~min}$ equilibration in a buffer solution containing $6 \mathrm{M}$ urea, $50 \mathrm{mM}$ Tris- $\mathrm{HCl}$ $\mathrm{pH} 8.8,30 \%(\mathrm{v} / \mathrm{v})$ glycerol and 2\% SDS, with a addition of $2 \%(\mathrm{w} / \mathrm{v})$ DTT in the first equilibration step and 2.5\% iodoacetamide in the second step, respectively. The SDSPAGE was performed with $12 \%$ slab gels in running buffer (20 mM Tris- $\mathrm{HCl}, 192 \mathrm{mM}$ glycine, 0.1\% SDS, pH 8.3) at a constant temperature of $15^{\circ} \mathrm{C}$ by using the Ettan DALTsix Electrophoresis System (GE Healthcare, Uppsala, Sweden) for $6 \mathrm{~h}$ at $230 \mathrm{~V}$. SDS-PAGE protein marker (Bio-Rad, Hercules, CA) and liner pH arrangement of IPG strips were used to indicate the $\mathrm{pI}$ and molecular mass of the proteins. The 2-D gels were stained by colloidal Coomassie Brilliant Blue G-250 [85]. Briefly, gels were fixed in a solution of $40 \%(\mathrm{v} / \mathrm{v})$ methanol and $10 \%(\mathrm{v} / \mathrm{v})$ acetic acid for $40 \mathrm{~min}$, washed with purified water for $3 \times 15 \mathrm{~min}$, stained overnight in a staining solution [0.12\% Coomassie Brilliant Blue G-250, 20\% (v/v) methanol, 10\% (v/v) phosphate acid, $\left.10 \%(\mathrm{w} / \mathrm{v})\left(\mathrm{NH}_{4}\right)_{2} \mathrm{SO}_{4}\right]$, and then destained with purified water until the background was clear. All these staining steps were conducted on the shaker at room temperature.
Gel images were acquired using Epson Scanner (Seiko Epson Corporation, Japan) at 300 dpi resolution. Image analysis was performed with PDQuest version 8.0.1 (BioRad, Hercules, CA, USA). The software was used to perform background subtraction, Gaussian fitting, gel alignment, spot detection, matching and normalization. The parameters used to spot detection were as follow: sensitivity 6.05 , size scale 3 , min peak 600 , and local regression model was selected to conduct spot normalization. After manual processing, the candidate spots in all triplicate gels were submitted to $t$-test analysis. There was no log transform (or other suitable transform) of the intensities taken prior to analysis when PDquest software was used to process the spot data. The spots, which had both 2 -fold cut-off and a $P$-value of less than 0.05 by statistical test were considered differentially expressed protein spots.

\section{Protein identification by MS/MS and bioinformatic analysis of proteins}

Spots were excised from the colloidal Coomassie Brilliant Blue stained gels and plated into a 96-well microtitre plate. Excised spots were firstly destained twice with $60 \mu \mathrm{L}$ of $50 \mathrm{mM} \mathrm{NH} \mathrm{NCO}_{3}$ and $50 \%(\mathrm{v} / \mathrm{v})$ acetonitrile and then dried twice with $60 \mu \mathrm{L}$ of acetonitrile. Afterwards, the dried pieces of gels were incubated in icecold digestion solution (trypsin $12.5 \mathrm{ng} / \mu \mathrm{L}$ and $20 \mathrm{mM}$ $\mathrm{NH}_{4} \mathrm{HCO}_{3}$ ) for $20 \mathrm{~min}$ and then transferred into a $37^{\circ} \mathrm{C}$ incubator for digestion overnight. Peptides in the supernatant were collected after extraction twice with $60 \mu \mathrm{L}$ extract solution $[5 \%(\mathrm{v} / \mathrm{v})$ formic acid in $50 \%(\mathrm{v} / \mathrm{v})$ acetonitrile]. The resulting peptide solution was dried under the protection of $\mathrm{N}_{2}$. Before MS/MS analysis, the pellet was redissolved in $0.8 \mu \mathrm{L}$ matrix solution $[5 \mathrm{mg} / \mathrm{mL}$ $\alpha$-cyano-4-hydroxy-cinnamic acid diluted in $0.1 \%$ trifluoroacetic acid (TFA), 50\% (v/v) acetonitrile]. Then the mixture was spotted onto a MALDI target plate $(A B$ SCIEX). MS analysis of peptide was performed on an $A B$ SCIEX $5800 \mathrm{TOF} / \mathrm{TOF}$. The UV laser was operated at a $400 \mathrm{~Hz}$ repetition rate with wavelength of $355 \mathrm{~nm}$. The accelerated voltage was operated at $20 \mathrm{kV}$, and mass resolution was maximized at $1600 \mathrm{Da}$. Myoglobin digested with trypsin was used to calibrate the mass instrument with internal calibration mode. All acquired spectra of samples were processed using TOF/TOF Explorer ${ }^{\text {mix }}$ Software (AB SCIEX) in a default mode. The data were searched by GPS Explorer (Version 3.6) with the search engine MASCOT (Version 2.3, Matrix Science Inc, Boston, MA). The search parameters were as follow: viridiplantae database (1850050 sequences; 642453415 residues), trypsin digest with one missing cleavage, MS tolerance was set at $100 \mathrm{ppm}, \mathrm{MS} / \mathrm{MS}$ tolerance was set at $0.6 \mathrm{Da}$. Protein with ion scores greater than 75 were considered statistically significant $(P<0.05)$ and accepted. 
Ions score is calculated as $-10 \times \log (P)$, where $P$ is the probability that the observed match is a random event.

Bioinformatic analysis of proteins was performed according to Yang et al. [16].

\section{PCA and correlation analysis}

The differentially expressed proteins derived from $\mathrm{Mg}$ deficient $C$. sinensis leaves and roots were transformed for the PCA using the Unscrambler (version 10.0.1, Camo Software Inc., Woodbridge, NJ, USA). The PCA loading plots were used to determine the separation of the differentially expressed proteins based on the presence and absence of $\mathrm{Mg}$ in $\mathrm{C}$. sinensis leaves and roots. In this system, we used each protein response as predictor variables, whereas treatment factor (control versus Mg-deficiency) was considered to be response variable. The treatment factor was introduced as separate categorical variables [reading either -1 (Mg-deficiency) or 1 (control)]. The PCA loading plots were performed in triplicate $(n=3)$.

Pearson correlation analysis was performed to determine the relationships between the differentially expressed proteins derived from $\mathrm{Mg}$-deficient $C$. sinensis leaves and roots. Pearson correlation coefficients were obtained by subjecting the data set with correlation procedure (PROC CORR) in SAS version 8.02 to determine the effect of $\mathrm{Mg}$ deficiency in C. sinensis leaves and roots. Red and blue colors indicated a positive and negative correlation coefficient between the differentially expressed proteins derived from Mg-deficient $C$. sinensis leaves and roots. The correlation analysis was performed in triplicate $(n=3)$.

\section{Real time quantitative reverse transcription PCR (qRT-PCR) analysis}

Total RNA was extracted from the same root and leaf samples used for 2-DE analysis using Recalcirtant Plant Total RNA Extraction Kit (Centrifugal column type, Bioteke Corporation, China). About $2.0 \mu \mathrm{g}$ total RNA was used for first-strand cDNA synthesis using the RevertAid ${ }^{\mathrm{mx}}$ First-Strand cDNA Synthesis Kit (Thermo Scientific, Massachusetts, USA) following the manufacturer's instructions. The resulting cDNA was diluted 50-fold using Tris-EDTA buffer $(10 \mathrm{mM}$ Tris, $50 \mathrm{mM} \mathrm{NaCl}$, $1 \mathrm{mM}$ EDTA, pH 7.8). Gene-specific primers were designed using Primer Software Version 5.0 (PREMIER Biosoft International, CA, USA) according to the corresponding sequences of selected proteins in Citrus genome (http://phytozome.jgi.doe.gov/pz/portal.html\#! info?alias=Org_Cclementina). The sequences of the F and $\mathrm{R}$ primers used are given in Additional file 3. qRTPCR was performed using a SYBR ${ }^{\circ}$ Premix Ex Taq ${ }^{\text {Tix }}$ (Tli RNaseH Plus, TaKaRa, Japan) with the Step One Plus Real-Time System (Applid Biosystems, CA, USA) in an Eco Real-Time PCR System (Illumina, CA, USA). The cycling conditions were $15 \mathrm{~s}$ at $95^{\circ} \mathrm{C}$, followed by 40 cycles of $95^{\circ} \mathrm{C}$ for $5 \mathrm{~s}, 65^{\circ} \mathrm{C}$ for $34 \mathrm{~s}$. Samples for qRT-PCR were run in three biological replicates with two technical replicates. Relative gene expression was calculated using ddCt algorithm. For the normalization of gene expression, citrus actin (GU911361.1) was used as an internal standard and the leaves from control plants were used as reference sample, which was set to 1 .

\section{Experimental design and statistical analysis}

There were 40 seedlings ( 20 pots) per treatment in a completely randomized design. Experiments were performed with 3-10 replicates (primarily three). The same experimental samples were used for 2-DE and qRT-PCR analysis. Differences among treatments were separated by the unpaired $t$-test at $P<0.05$ level.

\section{Availability of supporting data}

The mass spectrometry proteomics data have been deposited to the ProteomeXchange Consortium via the PRIDE partner repository with the dataset identifier PXD001871.

\section{Additional files}

Additional file 1: Differentially expressed proteins in Mg-deficient leaves (A) and roots (B) as compared with control ones.

Additional file 2: Relative expression of three marker genes for jasmonate signalling in control and $\mathrm{Mg}$-deficient roots.

Additional file 3: Specific primer pairs used for qRT-PCR expression analysis.

\section{Competing interests}

The authors declare that they have no competing interests.

\section{Authors' contribution}

HYP carried out most of the experiments and drafted the manuscript. YPQ participated in the design of the study. JL performed the principal component analysis and pearson correlation coefficient matrix analysis, and revised the manuscript. LTY participated in the design of the study and coordination. PG performed the statistical analysis. HXJ performed the statistical analysis. LSC designed and directed the study and revised the manuscript. All authors have read and approved the final manuscript.

\section{Acknowledgements}

This study was financially supported by the earmarked fund for China Agriculture Research System.

\section{Author details}

${ }^{1}$ College of Resource and Environmental Science, Fujian Agriculture and Forestry University, Fuzhou 350002, China. ${ }^{2}$ College of Life Science, Fujian Agriculture and Forestry University, Fuzhou 350002, China. ${ }^{3}$ Institute of Horticultural Plant Physiology, Biochemistry, and Molecular Biology, Fujian Agriculture and Forestry University, Fuzhou 350002, China. ${ }^{4}$ Institute of Materia Medica, Fujian Academy of Medical Sciences, Fuzhou 350001, China. ${ }^{5}$ Department of Horticultural Science, Kyungpook National University, Daegu 702-701, ROK. ${ }^{6}$ Fujian Key Laboratory for Plant Molecular and Cell Biology, Fujian Agriculture and Forestry University, Fuzhou 350002, China. ${ }^{7}$ The Higher Educational Key Laboratory of Fujian Province for Soil Ecosystem Health and Regulation, Fujian Agriculture and Forestry University, Fuzhou 350002, China.

Received: 17 November 2013 Accepted: 9 March 2015 Published online: 31 March 2015 


\section{References}

1. Verbruggen $\mathrm{N}$, Hermans C. Physiological and molecular responses to magnesium nutritional imbalance in plants. Plant Soil. 2013;368:87-99.

2. Hermans C, Johnson GN, Strasser RJ, Verbruggen N. Physiological characterisation of magnesium deficiency in sugar beet: acclimation to low magnesium differentially affects photosystems I and II. Planta. 2004;220:344-55.

3. Hull RJ. Magnesium usage by turfgrasses. TurfGrass Trends. 1998;7(8):7-14.

4. Cakmak I, Kirkby EA. Role of magnesium in carbon partitioning and alleviating photooxidative damage. Physiol Plant. 2008;133:692-704.

5. Yang GH, Yang LT, Jiang HX, Wang P, Chen LS. Physiological impacts of magnesium-deficiency in citrus seedlings: photosynthesis, antioxidant system and carbohydrates. Trees - Struct Funct. 2012;26:1237-50.

6. Tang N, Li Y, Chen LS. Magnesium deficiency-induced impairment of photosynthesis in leaves of fruiting Citrus reticulata trees accompanied by up-regulation of antioxidant metabolism to avoid photooxidative damage. J Plant Nutr Soil Sci. 2012;175:784-93.

7. Terry N, Ulrich A. Effects of magnesium deficiency on the photosynthesis and respiration of leaves of sugar beet. Plant Physiol. 1974;54:379-81.

8. Yang LT, Yang GH, You X, Zhou CP, Lu YB, Chen LS. Magnesium deficiencyinduced changes in organic acid metabolism of Citrus sinensis roots and leaves. Biol Plant. 2013;57:481-6.

9. Igamberdiev AU, Kleczkowski LA. Implications of adenylate kinase-governed equilibrium of adenylates on contents of free magnesium in plant cells and compartments. Biochem J. 2001:360:225-31.

10. Cakmak I, Hengeler C, Marschner H. Partitioning of shoot and root dry matter and carbohydrates in bean plants suffering from phosphorus, potassium and magnesium deficiency. J Exp Bot. 1994;45:1245-50.

11. Chao YY, Chou TS, Kao CH. Involvement of abscisic acid and hydrogen peroxide in regulating the activities of antioxidant enzymes in leaves of rice seedlings under magnesium deficiency. Plant Growth Regul. 2012;66:1-8.

12. Hermans C, Vuylsteke M, Coppens F, Craciun A, Inzé D, Verbruggen N. Early transcriptomic changes induced by magnesium deficiency in Arabidopsis thaliana reveal the alteration of circadian clock gene expression in roots and the triggering of abscisic acid-responsive genes. New Phytol. 2010;187:119-31.

13. Hermans C, Vuylsteke M, Coppens F, Cristescu SM, Harren FJ, Inzé D, et al. Systems analysis of the responses to long-term magnesium deficiency and restoration in Arabidopsis thaliana. New Phytol. 2010;187:132-44.

14. Wang ZF, Wang ZH, Shi L, Wang $\amalg$, Xu FS. Proteomic alterations of Brassica napus root in response to boron deficiency. Plant Mol Biol. 2010;74:265-78.

15. Chapman HD. The mineral nutrition of citrus. In: Reuther W, Webber HJ, Batchelor LD, editors. The Citrus Industry, Volume 2. CA: Division of Agricultural Sciences, University of California; 1968. p. 127-89.

16. Yang LT, Qi YP, Lu YB, Guo P, Sang W, Feng $H$, et al. iTRAQ protein profile analysis of Citrus sinensis roots in response to long-term boron-deficiency. J Proteomics. 2013:93:179-206.

17. Gebert M, Meschenmoser K, Svidová S, Weghuber J, Schweyen R, Eifler K, et al. A root-expressed magnesium transporter of the MRS2 /MGT gene family in Arabidopsis thaliana allows for growth in low- $\mathrm{Mg}^{2+}$ environments. Plant Cell. 2009;21:4018-30.

18. Yang PF, Chen H, Liang Y, Shen SH. Proteomic analysis of de-etiolated rice seedlings upon exposure to light. Proteomics. 2007;7:2459-68.

19. Sheen J. Feedback control of gene expression. Photosynth Res. 1994;39:427-38.

20. Ze Y, Zhou M, Luo L, Ji Z, Liu C, Yin S, et al. Effects of cerium on key enzymes of carbon assimilation of spinach under magnesium deficiency. Biol Trace Elem Res. 2009:131:154-64.

21. Mate CJ, Hudson GS, Von Caemmerer S, Evans JR, Andrews TJ. Reduction of ribulose bisphosphate carboxylase activase levels in tobacco (Nicotiana tabacum) by antisense RNA reduces ribulose bisphosphate carboxylase carbamylation and impairs photosynthesis. Plant Physiol. 1993;102:1119-28

22. Li Y, Liu XH, Zhuang WM. The effect of magnesium deficiency on photosynthesis of longan (Dimocarpus longana Lour.) seedlings. Acta Hort Sin. 2001;28:101-6.

23. Liu H, Chen X, Chen R, Song S, Sun G. Effects of magnesium deficiency on photosynthesis characteristic of flowering Chinese cabbage. Acta Hort Sin. 2006;33:311-6.

24. Hajirezaei MR, Peisker M, Tschiersch H, Palatnik JF, Valle EM, Carrillo N, et al. Small changes in the activity of chloroplastic NADP ${ }^{+}$-dependent ferredoxin oxidoreductase lead to impaired plant growth and restrict photosynthetic activity of transgenic tobacco plants. Plant J. 2002;29:281-93.

25. Palatnik JF, Tognetti VB, Poli HO, Rodríguez RE, Blanco N, Gattuso M, et al. Transgenic tobacco plants expressing antisense ferredoxin-NADP $(H)$ reductase transcripts display increased susceptibility to photooxidative damage. Plant J. 2003;35:332-41.

26. Price GD, Evans JR, Voncaemmerer S, Yu JW, Badger MR. Specific reduction of chloroplast glyceraldehyde-3-phosphate dehydrogenase-activity by antisense $\mathrm{RNA}$ reduces $\mathrm{CO}_{2}$ assimilation via a reduction in ribulose-bisphosphate regeneration in transgenic tobacco plants. Planta. 1995;195:369-78.

27. Stimler K, Berry JA, Yakir D. Effects of carbonyl sulfide and carbonic anhydrase on stomatal conductance. Plant Physiol. 2012;158:524-30.

28. Ito H, Iwabuchi M, Ogawa K. The sugar-metabolic enzymes aldolase and triose-phosphate isomerase are targets of glutathionylation in Arabidopsis thaliana:detection using biotinylated glutathione. Plant Cell Physiol. 2003;44:655-60.

29. Haake V, Zrenner R, Sonnewald U, Stitt M. A moderate decrease of plastid aldolase activity inhibits photosynthesis, alters the levels of sugars and starch, and inhibits growth of potato plants. Plant J. 1998;14:147-57.

30. Yadav SK, Singla-Pareek SL, Reddy MK, Sopory SK. Transgenic tobacco plants overexpressing glyoxalase enzymes resist an increase in methylglyoxal and maintain higher reduced glutathione levels under salinity stress. FEBS Let. 2005;579:6265-71.

31. Scheibe R. Malate valves to balance cellular energy supply. Physiol Plant. 2004;120:21-6.

32. Hebbelmann I, Selinski J, Wehmeyer C, Goss T, Voss I, Mulo P, et al. Multiple strategies to prevent oxidative stress in Arabidopsis plants lacking the malate valve enzyme NADP-malate dehydrogenase. J Exp Bot. 2012;63:1445-59.

33. Araújo WL, Nunes-Nesi A, Osorio S, Usadel B, Fuentes D, Nagy R, et al. Antisense inhibition of the iron-sulphur subunit of succinate dehydrogenase enhances photosynthesis and growth in tomato via an organic acid-mediated effect on stomatal aperture. Plant Cell. 2011:23:600-27.

34. Gupta AK, Kaur N. Carbohydrate Reserves in Plants - Synthesis and Regulation Amsterdam, The Netherlands: Elsevier; 2000.

35. Schoor S, Farrow S, Blaschke H, Lee S, Perry G, Von Schwartzenberg K, et al Adenosine kinase contributes to cytokinin interconversion in Arabidopsis. Plant Physiol. 2011;157:659-72.

36. Weretilnyk EA, Alexander KJ, Drebenstedt M, Snider JD, Summers PS, Moffatt BA. Maintaining methylation activities during salt stress. The involvement of adenosine kinase. Plant Physiol. 2001;125:856-65.

37. Kim YH, Lim S, Yang KS, Kim CY, Kwon SY, Lee HS, et al. Expression of Arabidopsis NDPK2 increases antioxidant enzyme activities and enhances tolerance to multiple environmental stresses in transgenic sweetpotato plants. Mol Breeding. 2009;24:233-44.

38. Moon $\mathrm{H}$, Lee $\mathrm{B}$, Choi G, Shin D, Prasad DT, Lee $\mathrm{O}$, et al. NDP kinase 2 interacts with two oxidative stress-activated MAPKs to regulate cellular redox state and enhances multiple stress tolerance in transgenic plants. Proc Natl Acad Sci U S A. 2003;100:358-63.

39. Kato-Noguchi H. Low temperature acclimation mediated by ethanol production is essential for chilling tolerance in rice roots. Plant Signal Behav. 2008;3:202-3.

40. Peters JS, Frenkel C. Relationship between alcohol dehydrogenase activity and low-temperature in two maize genotypes, Silverado F1 and Adh 1 Adh2- doubly null. Plant Physiol Biochem. 2004;42:841-6.

41. Onda Y, Matsumura T, Kimata-Ariga Y, Sakakibara H, Sugiyama T, Hase T. Differential interaction of maize root ferredoxin: NADP ${ }^{+}$oxidoreductase with photosynthetic and non-photosynthetic ferredoxin isoproteins. Plant Physiol. 2000;123:1037-45.

42. Xu Y, Gianfagna T, Huang B. Proteomic changes associated with expression of a gene (ipt) controlling cytokinin synthesis for improving heat tolerance in a perennial grass species. J Exp Bot. 2010;61:3273-89.

43. Lange PR, Geserick C, Tischendorf G, Zrenner R. Functions of chloroplastic adenylate kinases in Arabidopsis. Plant Physiol. 2008;146:492-504.

44. Bouny M, Saglio P. Glycolytic flux and hexokinase activities in anoxic maize root tips acclimated by hypoxic pretreatment. Plant Physiol. 1996;111:187-94.

45. Cho Jl, Ryoo N, Ko S, Lee SK, Lee J, Jung KH, et al. Structure, expression, and functional analysis of the hexokinase gene family in rice (Oryza sativa L.). Planta. 2006:224:598-611.

46. Bolouri-Moghaddam MR, Le Roy K, Xiang L, Rolland F, Van den Ende W. Sugar signalling and antioxidant network connections in plant cells. FEBS J. 2010;277:2022-37. 
47. Hideg É, Nagy T, Oberschall A, Dudits D, Vass I. Detoxification function of aldose/aldehyde reductase during drought and ultraviolet-B $(280-320 \mathrm{~nm})$ stresses. Plant, Cell Environ. 2003;26:513-22.

48. Oberschall A, Deák M, Török K, Sass L, Vass I, Kovács I, et al. A novel aldose/ aldehyde reductase protects transgenic plants against lipid peroxidation under chemical and drought stress. Plant J. 2000;24:437-46.

49. Turóczy Z, Kis P, Török K, Cserháti M, Lendvai A, Dudits D, et al. Overproduction of a rice aldo-keto reductase increases oxidative and heat stress tolerance by malondialdehyde and methylglyoxal detoxification. Plant Mol Biol. 2011;75:399-412.

50. Walford SA, Thomson JA, Farrant JM, Mundree SM. Isolation and characterisation of a novel dehydration-induced Grp94 homologue from the resurrection plant Xerophyta viscose. South Afr J Bot. 2004;70:741-50.

51. Alves M, Moes S, Jenö P, Pinheiro C, Passarinho J, Ricardo CP. The analysis of Lupinus albus root proteome revealed cytoskeleton altered features due to long-term boron deficiency. J Proteomics. 2011;74:1351-63.

52. Fu J, Momčilović I, Prasad PW. Roles of protein synthesis elongation factor EF-Tu in heat tolerance in plants. J Bot. 2012;2012:835836.

53. Lister R, Chew O, Lee MN, Heazlewood JL, Clifton R, Parker KL, et al. A transcriptomic and proteomic characterization of the Arabidopsis mitochondrial protein import apparatus and its response to mitochondrial dysfunction. Plant Physiol. 2004;134:777-89.

54. Craig KL, Tyers M. The F-box: a new motif for ubiquitin dependent proteolysis in cell cycle regulation and signal transduction. Prog Biophys Mol Biol. 1999;72:299-328

55. Lorick KL, Jensen JP, Fang S, Ong AM, Hatakeyama S, Weissman AM. RING fingers mediate ubiquitin-conjugating enzyme (E2)-dependent ubiquitination. Proc Natl Acad Sci U S A. 1999:96:11364-9.

56. El-Khatib RT, Hamerlynck EP, Gallardo F, Kirby EG. Transgenic poplar characterized by ectopic expression of a pine cytosolic glutamine synthetase gene exhibits enhanced tolerance to water stress. Tree Physiol. 2004;24:729-36.

57. Hoshida H, Tanaka Y, Hibino T, Hayashi Y, Tanaka A, Takabe T. Enhanced tolerance to salt stress in transgenic rice that overexpresses chloroplast glutamine synthetase. Plant Mol Biol. 2000;43:103-11.

58. Uthup TK, Ravindran M, Bini K, Thakurdas S. Divergent DNA methylation patterns associated with abiotic stress in Hevea brasiliensis. Mol Plant. 2011:4:996-1013

59. Kim BH, Cai X, Vaughn JN, Von Arnim AG. On the functions of the $h$ subunit of eukaryotic initiation factor 3 in late stages of translation initiation. Genome Biol. 2007:8:R60

60. Gong Z, Dong $\mathrm{CH}$, Lee $\mathrm{H}$, Zhu J, Xiong L, Gong D, et al. A DEAD box RNA helicase is essential for mRNA export and important for development and stress responses in Arabidopsis. Plant Cell. 2005;17:256-67.

61. Li D, Liu H, Zhang H, Wang X, Song F. OsBIRH1, a DEAD-box RNA helicase with functions in modulating defence responses against pathogen infection and oxidative stress. J Exp Bot. 2008:59:2133-46.

62. Keren I, Bezawork-Geleta A, Kolton M, Maayan I, Belausov E, Levy M, et al. AtnMat2, a nuclear-encoded maturase required for splicing of group-\| introns in Arabidopsis mitochondria. RNA. 2009;15:2299-311.

63. Keren I, Tal L. des Francs-Small CC, Araújo WL, Shevtsov S, Shaya F, Fernie AR, Small I, Ostersetzer-Biran O. nMAT1, a nuclear-encoded maturase involved in the trans-splicing of nad1 intron 1, is essential for mitochondrial complex I assembly and function. Plant J. 2012;71:413-26.

64. Furukawa R, Maselli A, Thomson SAM, Lim RWL, Stokes JV, Fechheimer M. Calcium regulation of actin crosslinking is important for function of the actin cytoskeleton in Dictyostelium. J Cell Sci. 2003;116:187-96.

65. Lavon R, Salomon R, Goldschmidt EE. Effect of potassium, magnesium, and calcium deficiencies on nitrogen constituents and chloroplast components in Citrus leaves. J Amer Soc Hort Sci. 1999:124:158-62.

66. Pozuelo JM, Espelie KE, Kolattukudy PE. Magnesium deficiency results in increased suberization in endodermis and hypodermis of corn roots. Plant Physiol. 1984;74:256-60.

67. Chen Y, Shin YK, Bassham DC. YKT6 is a core constituent of membrane fusion machineries at the Arabidopsis trans-Golgi network. J Mol Biol. 2005;350:92-101.

68. Pegoraro C, Krüger MM, Dos Santos RS, Mertz LM, Da Maia LC, Rombaldi CV, et al. Transcription of mitochondrial and chloroplast related genes in rice plants under anoxic stress. Plant Omics J. 2012;5:547-52.

69. Lipka V, Kwon C, Panstruga R. SNARE-ware: the role of SNARE-domain proteins in plant biology. Annu Rev Cell Dev Biol. 2007;23:147-74.
70. Sato-Izawa K, Nakaba S, Tamura K, Yamagishi Y, Nakano Y, Nishikubo N, et al. DWARF50 (D50), a rice (Oryza sativa L.) gene encoding inositol polyphosphate 5-phosphatase, is required for proper development of intercalary meristem. Plant, Cell Environ. 2012;35:2031-44.

71. Perera IY, Hung CY, Moore CD, Stevenson-Paulik J, Boss WF. Transgenic Arabidopsis plants expressing the type 1 inositol 5-phosphatase exhibit increased drought tolerance and altered abscisic acid signaling. Plant Cell. 2008;20:2876-93.

72. Gorinova N, Nedkovska M, Atanassov A. Cytochrome P450 monooxygenases as a tool for metabolization herbicides in plants. Biotechnol Biotechnol Eq. 2005;19(Special issue):105-15.

73. Narusaka Y, Narusaka M, Seki M, Umezawa T, Ishida J, Nakajima M, et al. Crosstalk in the responses to abiotic and biotic stresses in Arabidopsis: analysis of gene expression in cytochrome P450 gene superfamily by CDNA microarray. Plant Mol Biol. 2004;55:327-42.

74. Wasternack C. Jasmonates: an update on biosynthesis, signal transduction and action in plant stress response, growth and development. Ann Bot. 2007; 100:681-97

75. Hu T, Zeng H, Hu Z, Qv X, Chen G. Overexpression of the tomato 13lipoxygenase gene TomloxD increases generation of endogenous jasmonic acid and resistance to Cladosporium fulvum and high temperature. Plant Mol Biol Rep. 2013;31:1141-9.

76. Lorenzo O, Roberto SR. Molecular players regulating the jasmonate signalling network. Curr Opin Plant Biol. 2005;8:532-40.

77. Lorenzo O, Chico JM, Sánchez-Serrano JJ, Solano R. JASMONATE-INSENSITIVE1 encodes a MYC transcription factor essential to discriminate between different jasmonate-regulated defense responses in Arabidopsis. Plant Cell. 2004;16:1938-50

78. Geerinck J, Pauwels L, De Jaeger G, Goossens A. Dissection of the oneMegaDalton JAZ1 protein complex. Plant Signal Behav. 2010;5:1039-41.

79. Shintani D, Roesler K, Shorrosh B, Savage L, Ohlrogge J. Antisense expression and overexpression of biotin carboxylase in tobacco leaves. Plant Physiol. 1997;114:881-6.

80. Otsuka M, Kenmoku H, Ogawa M, Okada K, Mitsuhashi W, Sassa T, et al. Emission of ent-kaurene, a diterpenoid hydrocarbon precursor for gibberellins, into the headspace from plants. Plant Cell Physiol. 2004:45:1129-38.

81. Fleet CM, Yamaguchi S, Hanada A, Kawaide H, David CJ, Kamiya Y, et al. Overexpression of AtCPS and AtKS in Arabidopsis confers increased ent-kaurene production but no increase in bioactive gibberellins. Plant Physiol. 2008;132:830-9.

82. Kushizaki M. An extraction procedure of plant materials for the rapid determination of $\mathrm{Mn}, \mathrm{Cu}, \mathrm{Zn}$ and $\mathrm{Mg}$ by the atomic absorption analysis. J Sci Soil Manure Jpn. 1968;39:489-90.

83. Bradford MM. A rapid and sensitive method for quantitation of microgram quantities of protein utilizing the principle of protein-dye binding. Anal Biochem. 1976;72:248-54

84. Fan M, Zhu J, Richards C, Brown KM, Lynch JP. Physiological roles for aerenchyma for phosphorus-stressed roots. Funct Plant Biol. 2003;30:493-506.

85. Anderson NL, Esquer-Blasco R, Hofmann JP, Anderson NG. A two-dimensional gel database of rat liver proteins useful in gene regulation and drug effects studies. Electrophoresis. 1991;12:907-30.

\section{Submit your next manuscript to BioMed Central and take full advantage of:}

- Convenient online submission

- Thorough peer review

- No space constraints or color figure charges

- Immediate publication on acceptance

- Inclusion in PubMed, CAS, Scopus and Google Scholar

- Research which is freely available for redistribution 